\title{
New Mothers' Labour Force Participation in Italy: The Role of Job Characteristics
}

\section{Massimiliano Bratti — Emilia Del Bono - Daniela Vuri}

Abstract. In this paper we use newly available individual-level data from the Longitudinal Survey of Italian Households to investigate the factors associated with female labour force participation after the birth of the first child. We focus on the role of pre-marital job characteristics and find that new mothers who worked without a contract are less likely to participate, while those who worked in the public sector or in a large private firm have a higher probability of being in the labour force after childbearing. We suggest that these effects could be at least partly attributed to differences in the level of job protection and employment stability enjoyed by workers. This implies that in Italy women with highly protected and stable jobs might find it easier to combine career and family, whereas those who are less sheltered by the legislation might be more likely to be inactive after becoming mothers.

Massimiliano Bratti - Emilia Del Bono - Daniela Vuri (author for correspondence), Department of Economics, University of Florence, CHILD (Turin) and IZA (Bonn), via delle Pandette 9, Edificio D6, 50127 Florence, Italy. Tel: +39055 4374567; Fax: +39055 4374905; E-mail: daniela.vuri@unifi.it.

We acknowledge the University of Milano Bicocca, the University of Trento, and the University of Bologna for the use of data from the Indagine longitudinale sulle famiglie italiane, 1997 (scientific coordinator: A. Schizzerotto). Earlier versions of this paper were presented at the EALE Conference (Seville), the XVIII AIEL Conference (Messina), the RES Conference (University of Wales, Swansea), the European University Institute (Florence), ISFOL (Rome), the University of Oxford, the University of Sussex, CSEF (University of Salerno), IRS (Milan), the University of Modena, the DG Employment of the European Commission, and the ChilD Annual Workshop (University of Bari). We wish to thank Francesca Bettio, Daniela Del Boca, Andrea Ichino, Adriaan Kalwij, Paolo Sestito, Stefano Staffolani, Frank Vella, and an anonymous referee for useful comments on earlier drafts. Any errors and omissions are our own responsibility. Funding from the Italian Ministry of Work and Welfare is gratefully acknowledged. 


\section{Introduction}

In March 2000 the European Council in Lisbon set out a 10-year strategy to make the European Union (EU) the world's most dynamic and competitive economy. One of the goals of the Lisbon strategy was to increase female employment rates in the EU to at least 60 per cent by 2010. Eight out of the present 15 EU countries already reach this target, with France being very close to achieving it in the next couple of years. Italy, on the contrary, not only is at the very bottom of the ranking but appears to be very far behind. According to the Italian National Statistical Institute (ISTAT) official data for 2003, in Italy only 42 per cent of women aged 14-64 are in employment, and less than one in two participates in the labour force.

The incompatibility between child rearing and work in the marketplace is often advocated as the main reason for the low labour market participation of Italian women. Quite paradoxically, however, fertility rates in Italy have been below the replacement level of two children per woman for over two decades, and the current rate is one of the lowest in Europe (1.26 children per woman in 2003). This would suggest that combining family and working responsibilities is so difficult that even women with one child are unlikely to participate in the labour market. If this is indeed the case, understanding the factors that enable women to retain a strong labour force attachment around childbirth is very important, especially because if women withdraw from the labour force due to childbearing it can be quite difficult for them to return to activity.

We are aware of very little empirical research that investigates female labour force participation (LFP hereafter) patterns around childbirth in Italy. Previous research on Italian female LFP and fertility has mainly focused on individual and institutional factors and almost completely neglected the potential role played by job characteristics. Although personal characteristics, such as educational levels, and institutional features, such as the availability of childcare and part-time jobs, are paramount to female LFP, we think that job characteristics deserve more attention. Indeed, different job characteristics may imply different costs of non-participation. For example, high-wage jobs, jobs with greater promotion prospects, and more secure jobs will entail higher costs of a withdrawal. At the same time, there are jobs that offer working arrangements that make it easier to reconcile work and family, such as jobs with a reduced or a flexible working time. 
The goal of our paper is to use newly available Italian micro-data to shed some light on the role of pre-marital job characteristics on new mothers' LFP. In order to do so we use new information from the Longitudinal Survey of Italian Households ${ }^{1}$ (also LSIH hereafter) to analyse the decisions of married or co-habiting women to participate in the labour market during the first 3 years after the birth of the first child. We focus only on the period after the birth of the first child because, as documented in Solera (2003), Italian women are unlikely to experience a career break more than once in their lives and this usually occurs at the time of the birth of the first child.

Our results suggest that the degree of employment protection plays a role in determining labour force attachment after childbearing. This result is mainly reflected in significant differences among women according to the type of work contract, whereby women working in the informal sector have a probability of participating after the birth of their first child that is at least 12 per cent lower than women working with a permanent contract. We also find that women working in the public sector or in big private firms have a much higher post-birth participation probability than women working in small private firms. Because public sector jobs can be considered 'cycleproof' jobs in which workers enjoy a high degree of employment protection, and because the Italian employment protection legislation favours large firms' employees, our results seem to suggest that an important role is played by employment protection and job security in encouraging higher participation rates among new mothers.

Other factors analysed in this paper include the effect of variables related to a woman's human capital, such as her highest educational qualification achieved and past labour market experience, and the influence of her partner's characteristics. Because of their relevance for policy making, a particular emphasis is given to the role of parttime work and childcare. We find a positive, although only marginally significant, effect of past part-time work on LFP, and very strong evidence that the unavailability of either formal or informal childcare is negatively associated with new mothers' probability of LFP in the first 3 years after childbirth. While we cannot say much about the first effect, due to fact that part-time work in Italy is a very recent phenomenon, the second result confirms the findings of several other studies focusing on Italy. ${ }^{2}$

The structure of the paper is as follows. In the next section we discuss the most recent literature on female LFP and employment with particular reference to the role of job characteristics. Section 3 describes the data and the procedure of sample selection, and 
Section 4 discusses the econometric strategy and some empirical issues. In Section 5, we look at the main results, focusing first on the effect of job characteristics and then on other aspects, such as the availability of childcare. Section 6 summarizes our main findings and conclusions.

\section{Motivation and related literature}

Neoclassical models of female LFP (Becker, 1981; Cigno, 1991) posit that women compare the costs and benefits of LFP when deciding whether to participate in the labour market or not. The costs of participation are both pecuniary and related to job search and the purchase of external childcare, and non-pecuniary, such as those related to the reduction in time devoted to child rearing or leisure. The benefits of participation are also both pecuniary and related to the current wage and the future expected flow of labour income, and non-pecuniary due, for instance, to the personal selfesteem that may be derived from a satisfactory working life. It is clear that all the factors affecting these costs and benefits should be included when considering empirical models of female LFP around childbirth (see Nakamura and Nakamura, 1992).

Past empirical research related to Italy has mainly emphasized the role of individual characteristics, such as education (Bratti, 2003), or the institutional features of the Italian labour market, such as the availability of childcare (Del Boca and Vuri, 2005; Del Boca et al., 2005) or part-time jobs (Del Boca, 2002), on women's LFP or employment. However, almost all empirical work in Italy is based on the Survey of Household Income and Wealth (SHIW) of the Bank of Italy, which gathers data on current LFP or employment and on the current or the most recent job characteristics [see also earlier work by Colombino and Di Tommaso (1996) and Di Tommaso (1999)]. This implies that generally no information is provided on women's past working experience and job conditions.

The LSIH has clear advantages in this respect. It provides retrospective data on the whole working life of the sampled women and enables us to control for past job characteristics. The importance of job characteristics for new mothers' LFP may stem from the fact that some types of jobs entail higher costs of non-participation (or career interruptions) or may ensure a better balance between family and work. For instance, women in jobs with a high degree of human capital depreciation, where the costs of staying out of the labour 
market are very high, may provide a strong incentive to continuous participation or employment. On the other hand, women in jobs where working hours are shorter or more flexible may have advantages in reconciling work and child rearing and may show a higher labour force attachment after becoming mothers.

There is a relatively small, but nevertheless interesting, literature that looks at job and workplace characteristics in order to study female labour force attachment in conjunction with fertility. Desai and Waite (1991), for instance, find that occupational characteristics that raise the cost of a labour force withdrawal, such as jobspecific training, decrease the probability of leaving the labour market in the USA. A similar picture emerges from the study of Nakamura and Ueda (1999), who use data from Japan to investigate the determinants of job continuity of married women after childbirth, and find an important role of the working environment. In particular, they find significant differences across industries and a very strong negative effect of being a public servant on the probability of a career interruption after the first birth.

Gutiérrez-Domènech (2002) analyses Spanish women's employment and LFP after first birth and provides additional evidence in this respect. Using data from the Family and Fertility Survey (FFS) and focusing on women who were working 12 months before childbirth, she finds positive effects of past working experience and high occupational status and a negative effect of the percentage of women with fixed-term contracts at the national level on the probability of employment up to 10 years after childbirth. In the same study, additional evidence from the Encuesta de Población Activa (EPA) reveals positive effects of working in the public sector, permanent contracts, full-time contracts, and high tenure on the probability of employment between 6 and 9 months after first birth. When considering LFP rather than employment after first birth, only tenure, full-time work and high occupational status turn out to be positively related to women's participation.

More recently, Berg et al. (2003) investigate the role of highcommitment environments on the worker's perception that the employer is helping in balancing work and family responsibility using US data. They find positive effects of informal training, performance-related pay, and promotion opportunities in the workplace, and negative effects of long working hours and involuntary overtime. Moreover, factors that are likely to be positively correlated with job satisfaction turn out to have a significant positive effect on employees' ratings of the ability to balance work and family. 
In the light of these findings, we think that an analysis of the role of job characteristics on new mothers' LFP in Italy represents an interesting contribution to this literature.

\section{The LSIH data and sample description}

A largely unexplored and interesting source of data for our purposes is the LSIH. The survey is conducted by the University of Trento, the Istituto Trentino di Cultura, and the Italian Office of National Statistics (ISTAT) on a representative sample of Italian families. The first wave of the survey was carried out in 1997 and the second and third waves took place in 1999 and 2001, respectively. Our sample is derived from the 4,713 families interviewed in 1997 , as at the time of our study this was the only sweep publicly available. The data set includes retrospective information on the 10,423 adult members of the participating families. This allows us to construct the life history of each respondent in relation to the following aspects: timing of births, family formation and structure, education, work and occupation, social background, and geographical or residential mobility. ${ }^{3}$

With respect to past labour market experience, we are able to observe whether an individual was primarily in school, working, or engaged in some other activity from the age of 18 to the date of the interview. For those who were working, we have information on the sector and occupational qualification of the job, on whether an employment episode was full-time or part-time, on the type of contract, and on the hours usually worked during the week. For those who were engaged in other activities, it is possible to distinguish between the unemployment and out-of-the-labour-force states. The latter includes people who are retired, on parental leave, on temporary or permanent sickness leave, those who are carrying out the obligatory military service, students, and housewives.

The main weakness of the data set is that there are no income and earnings variables, except for total household net income and each member's contribution to it (in per cent) in 1995. However, educational attainment and occupational qualification variables are collected at a very disaggregated level and are available at various points in time, so that they can be considered good proxies of an individual's wage and family income.

The initial sample consists of 5,469 women aged 18 or above who were interviewed in 1997. Of these women, 4,143 formed at least 
one marriage or one co-habiting relationship and 3,732 of them have at least one child by the time of the interview. The mean age at first union for this sample is about 24.2 years, while the mean age at the birth of the first child is about 25.5 years. Official statistics for Italy reveal that in 1997 the mean age at first marriage for women was around 27.1 years and the mean age at the birth of the first child was 28.1 years (ISTAT). The difference between our data and official statistics can be explained by the fact that whereas the latter refer to period measures of the above indicators, the former are based on retrospective information. Given the trend towards postponement of marriage and maternity of the last decades, it is reasonable to expect that women in our sample would exhibit a younger age at first union and at first birth.

In order to control for the characteristics of the partner, we consider only women who had only one marriage or one co-habiting relationship, thus excluding single mothers and women who have remarried. ${ }^{4}$ This reduces the number of observations to 3,919 women, about 72 per cent of the original sample. ${ }^{5}$ We select only women born after 1940, in order to minimize the effect of recollection errors. We also exclude women with invalid data for the job histories, and those that are not observed for a 3-year window after the birth of the first child because this period defines our dependent variable. This means that women more than 57 years old, or those who had a child close to 1997 do not appear in our sample. Furthermore, we do not take into account women who had a first birth within 7 months from the date of marriage to ensure that the variables collected at the time of marriage and used in the empirical analysis are predetermined with respect to the birth event (see Section 4).

With respect to the woman's participation history during the first 3 years after the first birth, we consider the period spent in maternity leave as participation as long as the total number of months of self-reported maternity leave does not exceed the compulsory period imposed by legislation. ${ }^{6}$ Moreover, we focus our empirical investigation on women who had at least one employment episode before marriage, excluding another 719 observations from our sample. This is because women who never worked before marriage are likely to have made a lifetime decision of inactivity, so that the analysis of LFP after childbirth is less relevant in this case. ${ }^{7}$

Dummy variables for missing values were generally introduced in order not to reduce further the number of observations. In a few additional cases, however, some observations need to be excluded because for certain variables the number of non-response cases is 
too small to be treated as a separate category. As a consequence, our final sample consists of 1,322 women, 1,090 of whom had their first child by 1995 . For this sample, we see that the average woman gets married at age 24.6, which is a figure very close to the mean for all women in our survey (24.2 years), but she has a child at age 26.5, almost 1 year later than the average woman in the whole data set. This difference results from the fact that we consider only women with some attachment to the labour force, who tend to postpone fertility decisions. If we were to consider also those women who never had an employment spell before marriage, we would observe a mean age at first birth of about 25.6 years, which is not statistically different from the 25.5 recorded for the original data set.

Table 1 reports some descriptive statistics for our selected sample. First, we see here that the fraction of new mothers working after the first birth is relatively constant over the 3 years after the birth, showing no sign of relevant changes. Table 2 looks at this aspect in more detail, disaggregating by birth cohort of the mother. As we can see, there are very small differences in the within-cohort rates of female participation over the 3-year window. In other words, there is no significant drop or rise in female participation rates after childbearing for any of the cohorts observed in our sample. On the other hand, significant differences emerge with respect to female participation rates across cohorts. As these cross-cohort differences will be in part explained by differences in observed characteristics and conditions of the labour market, which we can control for in our regressions, we will not be carrying out a separate analysis by birth cohort and use a pooled sample instead. ${ }^{8}$

Going back to Table 1 and looking at the type of contract held by the subject, we see a prevalence of permanent workers and only a low fraction of fixed-term contract workers. This is explained by the retrospective nature of the LSIH and by the fact that the diffusion of fixed-term contracts is a recent phenomenon in Italy. Women are mainly working as white-collar workers in the service sector, in small firms, or in the public sector. The table also shows that the percentage of working experience spent in a part-time job is quite low, probably because of the fact that part-time work was a rare occurrence in Italy in the past decades. This is also confirmed by the fact that on average the women in our sample work about 40 hours per week.

We also see that turnover is quite low as on average about 85 per cent of a woman's total working experience before marriage is accounted for by the longest working episode. As we select only women with at least one employment episode before marriage, the 
Table 1. Sample descriptive statistics

\begin{tabular}{|c|c|c|c|}
\hline Variables & Mean & st. dev. & Observations \\
\hline First child & 0.82 & 0.38 & 1,322 \\
\hline Number of siblings at age $14^{\mathrm{a}}$ & 2.06 & 1.75 & 1,307 \\
\hline $\begin{array}{l}\text { In the labour force after } 12 \text { months since } \\
\text { the first child }\end{array}$ & 0.68 & 0.47 & 1,090 \\
\hline $\begin{array}{l}\text { In the labour force after } 24 \text { months since } \\
\text { the first child }\end{array}$ & 0.67 & 0.47 & 1,090 \\
\hline $\begin{array}{l}\text { In the labour force after } 36 \text { months since } \\
\text { the first child }\end{array}$ & 0.66 & 0.47 & 1,090 \\
\hline $\begin{array}{l}\text { Woman's working hours - longest job } \\
\text { before marriage }^{\mathrm{a}}\end{array}$ & 40.90 & 10.63 & 1,045 \\
\hline \multicolumn{4}{|l|}{$\begin{array}{l}\text { Woman's type of contract - longest job before } \\
\text { marriage }\end{array}$} \\
\hline Reference: permanent contract & 0.62 & 0.49 & 1,090 \\
\hline Fixed-term contract & 0.13 & 0.34 & 1,090 \\
\hline No contract & 0.13 & 0.34 & 1,090 \\
\hline Self-employed & 0.08 & 0.27 & 1,090 \\
\hline Missing & 0.03 & 0.18 & 1,090 \\
\hline \multicolumn{4}{|l|}{$\begin{array}{l}\text { Woman's occupation group - longest job } \\
\text { before marriage }\end{array}$} \\
\hline Reference: unskilled manual & 0.20 & 0.40 & 1,090 \\
\hline Entrepreneurs & 0.02 & 0.13 & 1,090 \\
\hline White collar — high & 0.33 & 0.47 & 1,090 \\
\hline White collar - low & 0.28 & 0.45 & 1,090 \\
\hline Skilled manual & 0.10 & 0.30 & 1,090 \\
\hline \multicolumn{4}{|l|}{$\begin{array}{l}\text { Woman's sector of activity - longest job } \\
\text { before marriage }\end{array}$} \\
\hline Reference: private firm with $\leq 15$ employees & 0.32 & 0.47 & 1,090 \\
\hline Private firm with $16-75$ employees & 0.16 & 0.36 & 1,090 \\
\hline Private firm with 76-150 employees & 0.06 & 0.23 & 1,090 \\
\hline Private firm with $>150$ employees & 0.08 & 0.27 & 1,090 \\
\hline Public sector & 0.19 & 0.40 & 1,090 \\
\hline Missing & 0.15 & 0.36 & 1,090 \\
\hline \multicolumn{4}{|l|}{ Woman's work experience - at marriage } \\
\hline Per cent working experience in part-time jobs & 6.01 & 22.86 & 1,090 \\
\hline $\begin{array}{l}\text { Per cent working experience longest job } \\
\text { before marriage }\end{array}$ & 84.80 & 19.99 & 1,090 \\
\hline Working experience (months) & 71.30 & 44.82 & 1,090 \\
\hline \multicolumn{4}{|l|}{ Woman's unemployment - at marriage } \\
\hline Reference: never unemployed & 0.89 & 0.31 & 1,090 \\
\hline Less than or equal to 1 year & 0.06 & 0.24 & 1,090 \\
\hline More than 1 year & 0.05 & 0.22 & 1,090 \\
\hline Childcare not available & 0.05 & 0.22 & 1,090 \\
\hline \multicolumn{4}{|l|}{ Woman's education - at marriage } \\
\hline Reference: primary or no formal schooling & 0.27 & 0.45 & 1,090 \\
\hline Lower secondary school & 0.33 & 0.47 & 1,090 \\
\hline Upper secondary school & 0.32 & 0.47 & 1,090 \\
\hline University degree & 0.07 & 0.25 & 1,090 \\
\hline
\end{tabular}


Table 1. Continued

\begin{tabular}{lccc}
\hline Variables & Mean & st. dev. & Observations \\
\hline Unemployment rate after 12 months since & 7.01 & 4.15 & 1,090 \\
$\quad$ the first child & & & \\
Unemployment rate after 24 months since & 7.30 & 4.38 & 1,090 \\
$\quad$ the first child & 7.55 & 4.57 & 1,090 \\
Unemployment rate after 36 months since & & & \\
the first child & 27.86 & 4.20 & 1,004 \\
Partner's age - at marriage & & & \\
Partner's occupation group - at marriage & 0.13 & 0.33 & 1,090 \\
$\quad$ Reference: unskilled manual & 0.09 & 0.28 & 1,090 \\
Entrepreneurs & 0.14 & 0.35 & 1,090 \\
Professionals (self-employed) & 0.21 & 0.41 & 1,090 \\
White collar - high & 0.10 & 0.30 & 1,090 \\
White collar - low & 0.26 & 0.44 & 1,090 \\
Skilled manual & 0.07 & 0.26 & 1,090 \\
Missing & & & \\
Woman's birth cohort & 0.15 & 0.36 & 1,090 \\
Reference: 1940-44 & 0.23 & 0.42 & 1,090 \\
1945-49 & 0.19 & 0.39 & 1,090 \\
1950-54 & 0.19 & 0.39 & 1,090 \\
1955-59 & 0.16 & 0.37 & 1,090 \\
1960-64 & 0.07 & 0.26 & 1,090 \\
1965-69 & 0.01 & 0.10 & 1,090 \\
1970-77 & & & \\
Geographical area - at marriage & 0.23 & 0.42 & 1,090 \\
Reference: South & 0.33 & 0.47 & 1,090 \\
North West & 0.21 & 0.40 & 1,090 \\
North East & 0.15 & 0.36 & 1,090 \\
Centre & 0.08 & 0.27 & 1,090 \\
Isles & & & \\
\hline
\end{tabular}

Note: ${ }^{\text {a }}$ Refers to non-missing values only.

Table 2. Percentage of women participating to the labour market after first childbirth by birth cohort

\begin{tabular}{lccc}
\hline & \multicolumn{3}{c}{ Per cent participating women after first birth } \\
\cline { 2 - 4 } Cohort & 12 months & 24 months & 36 months \\
\hline $1940-44$ & 60.84 & 58.43 & 56.02 \\
$1945-49$ & 61.75 & 60.56 & 61.75 \\
$1950-54$ & 79.51 & 79.02 & 79.02 \\
$1955-59$ & 69.61 & 68.14 & 64.71 \\
$1960-64$ & 71.84 & 71.84 & 70.69 \\
$1965-69$ & 62.82 & 65.38 & 65.38 \\
$1970-77$ & 50.00 & 41.67 & 41.67 \\
\hline
\end{tabular}

(C) CEIS, Fondazione Giacomo Brodolini and Blackwell Publishing Ltd 2005. 
women in our sample show a relatively high amount of working experience before marriage. Other aspects related to the woman's amount of human capital are reflected in her experience of unemployment, here represented by a categorical variable assuming three possible values. We also include in our regression the total unemployment rate in the region of residence at 12, 24, and 36 months after the birth of the first child, in order to capture a potential discouraged worker effect that has been found elsewhere (see, for instance, Del Boca et al., 2000).

The LSIH includes a question on the availability of childcare during the first 3 years after child birth. The exact formulation of the question is: 'In the first 3 years after the birth did you receive childcare help from your relatives, other people or institutions (e.g. kindergarten)?'. There are four possible answers: 1 'yes, it was free', 2 'yes, it was not free', 3 'no, we had no need', 4 'no, we did not have availability of relatives/other persons/institutions'. As the first three answers could be endogenous with respect to women's employment decisions, we decided to use only the fourth answer. We therefore construct an indicator of childcare availability using a dummy variable with value one when childcare is not available from any of the three possible sources. Arguably, this variable is less affected by endogeneity problems, although we are possibly underestimating the problem as our table shows that only 5 per cent of women in our sample declare not to have access to any form of childcare.

\section{Econometric model and issues}

In this work we use newly available information from the working and family histories of the LSIH in order to analyse women's LFP decisions in the period immediately following the birth of the first child. Even if the main aim of our paper is to consider the effect of past job characteristics, we also control for an individual's and her partner's attributes, her past working experience, and the availability of informal or formal childcare. This is in order to determine what are the main factors associated with a higher degree of LFP of new mothers.

There are two main issues that we need to deal with in the empirical analysis. First, it is possible that a woman's past job characteristics are endogenous with respect to LFP choices following the birth of a child. Second, as we analyse new mothers' labour market participation, there is the possibility that selection into motherhood 
may affect our results if there are unobserved factors that influence both women's fertility and their post-birth participation decisions. The following two subsections describe how our empirical strategy tackles these problems.

\subsection{Potential endogeneity of past job characteristics with respect to LFP after childbearing}

As our dependent variable is represented by women's LFP after first birth, including past job characteristics among the regressors poses a problem because these variables might be endogenous with respect to LFP around first birth. A similar issue arises with respect to previous past working experience, which is included in order to proxy for human capital accumulation and wages. This problem remains even if these variables are taken before the birth of the child, so that they are predetermined with respect to fertility decisions and subsequent participation choices. This is because there might be some unobserved characteristics of an individual that affect her past working experience, type of job, and, at the same time, her LFP status after first birth, so that the estimated effects of the regressors on the dependent variable may simply reflect women's unobserved heterogeneity.

Although we substantially reduce the degree of heterogeneity in our sample by considering only individuals who experienced at least one employment episode before marriage and control for many characteristics of a woman and her partner, this is only a partial solution to the problem. A full account of the endogeneity of past working experience and previous job characteristics would require the adoption of an instrumental variables strategy or a joint modelling approach. However, as we consider several aspects of a woman's past employment experience and numerous features of her previous jobs, and because of the absence of valid identifying exclusion restrictions, any attempt in this direction is likely to be difficult to pursue.

On the other hand, although the endogeneity of past labour market experience is likely to remain an issue in our analysis, we argue that the endogeneity of past job characteristics constitutes less of a problem. With respect to a situation in which the variables of interest are mainly choice variables for an individual (such as educational qualifications achieved), job characteristics are the outcome of the interaction between labour supply and labour demand. Women with certain unobserved traits may focus their search efforts towards jobs with certain characteristics, but this does not imply that they will 
be able to get their preferred jobs. In fact, a woman's job characteristics will also be determined by general labour demand conditions and employers' decisions and this could partly attenuate the problems of endogeneity associated with the effect of these variables.

We decide against considering the characteristics of the last job before childbirth because these are more likely to be simultaneously determined with the occurrence and the timing of the first birth, and therefore also with a woman's later LFP decisions. Instead, we consider the characteristics of the longest job held by a woman before marriage. Alternatively, we could have chosen the characteristics of the last job held by the woman at the time of marriage, or indeed any other job episode that started before the birth of the child. Although the choice may seem arbitrary, there is a substantial degree of continuity in Italian women's working experiences and we will see that, whatever job episode preceding the birth of the child we take, our results are not significantly altered.

The continuity of employment histories is important because it makes it more likely that women started their longest pre-marital job well before marriage and first birth, and that these job characteristics are 'sufficiently exogenous' with respect to childbirth and subsequent participation choices to suggest a more interesting interpretation of their effects. At the same time, a high degree of permanence in the same job is key to ensure that pre-marital job characteristics are a good proxy of pre-birth job characteristics and therefore provide a good picture of the potential working conditions faced by a woman at the moment she plans her fertility and future participation.

There is substantial evidence of a high degree of continuity in women's employment histories in the LSIH data set. In particular, we compare the longest job before marriage, the last job at marriage, and the last job before childbirth. As we will see, for a substantial percentage of women these jobs are the same. Furthermore, as the survey records a different job whenever one or more of the characteristics of the current job change, and not only when there is a change of employer, we find that with respect to certain job characteristics, which turn out to be important in our analysis, the jobs held by the individuals are even more similar.

Taking only women who had a first child by 1995, Table 3 shows that the percentage for whom the longest job at marriage is also the last job at marriage is about 79 per cent. If we cross-tabulate the type of sector (public versus private), in Table 4, we notice that the probability of remaining in the same sector is very high: 98.11 per cent of 
women stay in the public sector, while 92.57 per cent stay in the private sector. From the cross-tabulation of the characteristics of the work contract in Table 5, we see that the highest degrees of persistence are observed in the 'permanent' contract category (95.69 per cent) and the 'self-employed' category ( 88.64 per cent), but we also find high percentages along the main diagonal for the 'no contract' (about 83 per cent) and the 'fixed term' categories ( 85.52 per cent). Similar results are shown in Tables 6-8, which compare the longest job before marriage and the last job before childbirth, although in this case the degrees of persistence in the same job or in jobs with similar characteristics are lower because the employment episodes are likely to be more distanced in time.

So, even if in what follows we focus on the characteristics of the longest job at marriage, we show in the Appendix (Tables A1 and A2) that using the characteristics of the last job at marriage or those of the last job before childbirth does not change significantly our main results.

Table 3. Longest job versus last job before marriage

\begin{tabular}{lcc}
\hline Job & No. of observations & Per cent \\
\hline Different & 232 & 21.28 \\
Equal & 858 & 78.72 \\
Total & 1,090 & 100 \\
\hline
\end{tabular}

Table 4. Longest job versus last job before marriage: sector of activity

\begin{tabular}{lcccc}
\hline \multirow{2}{*}{$\begin{array}{l}\text { Longest job } \\
\text { at marriage }\end{array}$} & Public & Private & Missing & Total \\
\cline { 2 - 4 } & 208 & 2 & 2 & 212 \\
Public sector & $(98.11)$ & $(0.94)$ & $(0.94)$ & $(100)$ \\
Private sector & 30 & 698 & 26 & 754 \\
Missing & $(3.98)$ & $(92.57)$ & $(3.45)$ & $(100)$ \\
& 6 & 13 & 105 & 124 \\
Total & $(4.84)$ & $(10.48)$ & $(84.68)$ & $(100)$ \\
& 244 & 713 & 133 & 1,090 \\
& $(22.39)$ & $(65.41)$ & $(12.20)$ & $(100)$ \\
\hline
\end{tabular}

Note: Per cent in brackets.

(c) CEIS, Fondazione Giacomo Brodolini and Blackwell Publishing Ltd 2005. 
Table 5. Longest job versus last job before marriage: type of contract

\begin{tabular}{|c|c|c|c|c|c|c|}
\hline \multirow[b]{2}{*}{$\begin{array}{l}\text { Longest job } \\
\text { at marriage }\end{array}$} & \multicolumn{5}{|c|}{ Last job at marriage } & \multirow[b]{2}{*}{ Total } \\
\hline & $\begin{array}{l}\text { Fixed } \\
\text { term }\end{array}$ & Permanent & $\begin{array}{c}\text { No } \\
\text { contract }\end{array}$ & Self-employed & Missing & \\
\hline Fixed term & $\begin{array}{c}124 \\
(85.52)\end{array}$ & $\begin{array}{c}20 \\
(13.79)\end{array}$ & $\begin{array}{c}0 \\
(0.00)\end{array}$ & $\begin{array}{c}1 \\
(0.69)\end{array}$ & $\begin{array}{c}0 \\
(0.00)\end{array}$ & $\begin{array}{l}145 \\
(100)\end{array}$ \\
\hline Permanent & $\begin{array}{c}4 \\
(0.59)\end{array}$ & $\begin{array}{c}644 \\
(95.69)\end{array}$ & $\begin{array}{c}3 \\
(0.45)\end{array}$ & $\begin{array}{c}19 \\
(2.82)\end{array}$ & $\begin{array}{c}3 \\
(0.45)\end{array}$ & $\begin{array}{c}673 \\
(100)\end{array}$ \\
\hline No contract & $\begin{array}{c}4 \\
(2.72)\end{array}$ & $\begin{array}{c}15 \\
(10.2)\end{array}$ & $\begin{array}{c}122 \\
(82.99)\end{array}$ & $\begin{array}{c}5 \\
(3.4)\end{array}$ & $\begin{array}{c}1 \\
(0.68)\end{array}$ & $\begin{array}{c}147 \\
(100)\end{array}$ \\
\hline Self-employed & $\begin{array}{c}1 \\
(1.14)\end{array}$ & $\begin{array}{c}9 \\
(10.23)\end{array}$ & $\begin{array}{c}0 \\
(0.00)\end{array}$ & $\begin{array}{c}78 \\
(88.64)\end{array}$ & $\begin{array}{c}0 \\
(0.00)\end{array}$ & $\begin{array}{c}88 \\
(100)\end{array}$ \\
\hline Missing & $\begin{array}{c}2 \\
(5.41)\end{array}$ & $\begin{array}{c}8 \\
(21.62)\end{array}$ & $\begin{array}{c}0 \\
(0.00)\end{array}$ & $\begin{array}{c}1 \\
(2.70)\end{array}$ & $\begin{array}{c}26 \\
(70.27)\end{array}$ & $\begin{array}{c}37 \\
(100)\end{array}$ \\
\hline Total & $\begin{array}{c}135 \\
(12.39)\end{array}$ & $\begin{array}{c}696 \\
(63.85)\end{array}$ & $\begin{array}{c}125 \\
(11.47)\end{array}$ & $\begin{array}{c}104 \\
(9.54)\end{array}$ & $\begin{array}{c}30 \\
(2.75)\end{array}$ & $\begin{array}{l}1,090 \\
(100)\end{array}$ \\
\hline
\end{tabular}

Note: Per cent in brackets.

Table 6. Longest job before marriage versus last job before first birth

\begin{tabular}{lcc}
\hline Job & No. of observations & Per cent \\
\hline Different & 347 & 31.83 \\
Equal & 743 & 68.17 \\
Total & 1,090 & 100 \\
\hline
\end{tabular}

Table 7. Longest job before marriage versus last job before first birth: sector of activity

\begin{tabular}{lcccc}
\hline \multirow{2}{*}{$\begin{array}{l}\text { Longest job } \\
\text { at marriage }\end{array}$} & \multicolumn{3}{c}{ Last job at childbearing } & \\
\cline { 2 - 4 } & Public & Private & Missing & Total \\
\hline Public sector & 203 & 4 & 5 & 212 \\
& $(95.5)$ & $(1.89)$ & $(2.36)$ & $(100)$ \\
Private sector & 44 & 667 & 43 & 754 \\
Missing & $(5.84)$ & $(88.46)$ & $(5.70)$ & $(100)$ \\
& 9 & 12 & 103 & 124 \\
Total & $(7.29)$ & $(9.68)$ & $(83.06)$ & $(100)$ \\
& 256 & 683 & 151 & 1,090 \\
& $(23.49)$ & $(62.66)$ & $(13.85)$ & $(100)$ \\
\hline
\end{tabular}

Note: Per cent in brackets. 
Table 8. Longest job before marriage versus last job before first birth: type of contract

\begin{tabular}{lcccccc}
\hline \multirow{2}{*}{$\begin{array}{l}\text { Longest job } \\
\text { before } \\
\text { marriage }\end{array}$} & $\begin{array}{c}\text { Fixed } \\
\text { term }\end{array}$ & Permanent & $\begin{array}{c}\text { No } \\
\text { contract }\end{array}$ & Self-employed & Missing & Total \\
\cline { 2 - 6 } Fixed term & 112 & 29 & 0 & 4 & 0 & 145 \\
& $(77.24)$ & $(20.00)$ & $(0.00)$ & $(2.76)$ & $(0.00)$ & $(100)$ \\
Permanent & 11 & 620 & 7 & 29 & 6 & 673 \\
& $(1.63)$ & $(92.12)$ & $(1.04)$ & $(4.31)$ & $(0.89)$ & $(100)$ \\
No contract & 7 & 19 & 112 & 8 & 1 & 147 \\
& $(4.76)$ & $(12.93)$ & $(76.19)$ & $(5.44)$ & $(0.68)$ & $(100)$ \\
Self-employed & 1 & 9 & 0 & 78 & 0 & 88 \\
& $(1.14)$ & $(10.23)$ & $(0.00)$ & $(88.64)$ & $(0.00)$ & $(100)$ \\
Missing & 0 & 10 & 0 & 2 & 25 & 37 \\
& $(0)$ & $(27.03)$ & $(0.00)$ & $(5.41)$ & $(67.57)$ & $(100)$ \\
Total & 131 & 687 & 119 & 121 & 31 & 1,090 \\
& $(12.02)$ & $(63.03)$ & $(10.92)$ & $(11.10)$ & $(2.84)$ & $(100)$ \\
\hline
\end{tabular}

Note: Per cent in brackets.

\subsection{Potential endogeneity of LFP with respect to childbirth}

The other main issue we need to address in the empirical analysis is that of self-selection into motherhood. Labour force status of new mothers is observed only for women who had at least one child and, because the sample of mothers might not be a random sample of the whole female population with respect to some unobservable characteristics, a selection issue may arise and affect our estimates. In other words, if there are unobservable factors affecting both fertility and post-birth participation decisions, and the selection process underlying entry into motherhood is ignored, our estimates of the impact of the variables of interest on the participation decision of a woman after the birth of her first child will be inconsistent.

In order to explore this issue, we first look at fertility decisions and analyse the factors that affect the probability that a woman has a child by 1995. Table 9 reports the results of a standard probit model where the dependent variable assumes value one if a woman has a child and zero otherwise. The specification adopted here is chosen after performing a set of Wald tests. Other control variables that were initially included in the analysis were the religion of the woman, the firm industry, her husband's level of education, and her parents' education levels and occupational groups. All these variables turned out not to 
Table 9. Probability of first birth (probit model)

\begin{tabular}{|c|c|c|c|}
\hline Independent variables & $\begin{array}{c}\text { m.e. } \\
\text { (per cent) }\end{array}$ & & $\begin{array}{l}\text { st. err. } \\
\text { (per cent) }\end{array}$ \\
\hline $\begin{array}{l}\text { Woman's working hours - longest job } \\
\text { before marriage }\end{array}$ & -0.11 & * & 0.10 \\
\hline \multicolumn{4}{|l|}{$\begin{array}{l}\text { Woman's type of contract - longest job before } \\
\text { marriage }\end{array}$} \\
\hline Reference: permanent contract & - & & \\
\hline Fixed-term contract & 2.44 & & 2.44 \\
\hline No contract & 4.02 & & 2.73 \\
\hline Self-employed & 0.79 & & 4.40 \\
\hline Missing & -1.38 & & 5.55 \\
\hline \multicolumn{4}{|l|}{$\begin{array}{l}\text { Woman's occupation group - longest job } \\
\text { before marriage }\end{array}$} \\
\hline Reference: unskilled manual & - & & \\
\hline Entrepreneurs & -13.67 & & 9.77 \\
\hline White collar - high & -2.45 & & 3.23 \\
\hline White collar - low & -0.34 & & 2.70 \\
\hline Skilled manual & 0.50 & & 3.60 \\
\hline \multicolumn{4}{|l|}{$\begin{array}{l}\text { Woman's sector of activity — longest job } \\
\text { before marriage }\end{array}$} \\
\hline Reference: private firm with $<15$ employees & - & & \\
\hline Private firm with $16-75$ employees & 0.53 & & 2.55 \\
\hline Private firm with $75-150$ & -4.92 & & 5.67 \\
\hline Private firm with $>150$ & -5.82 & & 5.30 \\
\hline Public sector & -2.31 & & 3.26 \\
\hline Missing & 3.98 & * & 2.22 \\
\hline \multicolumn{4}{|l|}{ Woman's work experience - at marriage } \\
\hline Per cent working experience in part-time jobs & -0.02 & & 0.04 \\
\hline $\begin{array}{l}\text { Per cent working experience longest job } \\
\text { before marriage }\end{array}$ & 0.00 & & 0.04 \\
\hline Working experience (months) & -0.11 & $* * *$ & 0.02 \\
\hline \multicolumn{4}{|l|}{ Woman's unemployment - at marriage } \\
\hline Reference: never unemployed & - & & \\
\hline Less than or equal to 1 year & -5.32 & & 4.28 \\
\hline More than 1 year & -13.43 & $* * *$ & 5.12 \\
\hline \multicolumn{4}{|l|}{ Woman's education - at marriage } \\
\hline Reference: primary or no formal schooling & - & & \\
\hline Lower secondary school & -4.24 & $*$ & 2.43 \\
\hline Upper secondary school & -4.56 & & 3.03 \\
\hline University degree & -10.95 & $*$ & 6.17 \\
\hline Unemployment rate & -0.86 & $* *$ & 0.41 \\
\hline Partner's age - at marriage & -0.42 & $* *$ & 0.18 \\
\hline
\end{tabular}


Table 9. Continued

\begin{tabular}{|c|c|c|c|}
\hline Independent variables & $\begin{array}{c}\text { m.e. } \\
\text { (per cent) }\end{array}$ & & $\begin{array}{l}\text { st. err. } \\
\text { (per cent) }\end{array}$ \\
\hline \multicolumn{4}{|c|}{ Partner's occupation group — at marriage } \\
\hline Reference: unskilled manual & - & & \\
\hline Entrepreneurs & -2.24 & & 4.43 \\
\hline Professionals (self-employed) & -2.40 & & 3.96 \\
\hline White collar — high & -3.68 & & 3.44 \\
\hline White collar - low & -3.70 & & 3.27 \\
\hline Skilled manual & 1.33 & & 3.47 \\
\hline Missing & 2.63 & & 2.85 \\
\hline \multicolumn{4}{|l|}{ Woman's birth cohort } \\
\hline Reference: $1940-44$ & - & & \\
\hline $1945-49$ & 1.49 & & 1.96 \\
\hline $1950-54$ & -0.05 & & 2.23 \\
\hline $1955-59$ & -3.03 & & 2.56 \\
\hline $1960-64$ & -8.46 & $* *$ & 3.41 \\
\hline $1965-69$ & -38.19 & $* * *$ & 6.10 \\
\hline $1970-77$ & -75.38 & $* * *$ & 6.98 \\
\hline \multicolumn{4}{|l|}{ Geographical area - at marriage } \\
\hline Reference: South & - & & \\
\hline North West & -6.15 & * & 3.47 \\
\hline North East & -6.83 & $*$ & 3.67 \\
\hline Centre & -11.94 & $* * *$ & 4.35 \\
\hline Isles & -2.61 & & 3.26 \\
\hline \multicolumn{4}{|l|}{ Number of siblings at age 14} \\
\hline Number of siblings at age 14 & 3.91 & $* *$ & 1.16 \\
\hline Number of observations & & 1,322 & \\
\hline Wald $\left(\mathrm{chi}^{2}\right)$ & & 296.24 & \\
\hline Prob $>$ chi $^{2}$ & & 0.0000 & \\
\hline Pseudo- $R^{2}$ & & 0.3513 & \\
\hline
\end{tabular}

Notes: The dependent variable is a binary variable that takes on value one if a woman has a first birth by 1995 and zero otherwise. In addition to all the independent variables listed in the table, the probit model also includes the square of the number of siblings at age 14 (see footnote 9 on how their marginal effects are computed). We indicate with m.e. the marginal effects computed at the sample mean and with st. err. the relative heroskedasticity-robust standard errors. The Wald test is a test of the joint significance of all regressors other than the intercept.

*** Significant at the 1 per cent level; ** significant at the 5 per cent level; * significant at the 10 per cent level.

be significant at the 5 per cent statistical level, either individually or jointly, and were therefore excluded. Among the remaining independent variables we include the main characteristics of the woman and her partner measured at the time of marriage and several characteristics of the job of longest duration before marriage held by the woman. ${ }^{9}$ 
As expected, highly educated women have a lower probability of having a child even if this effect is only weakly significant, whereas the woman's past labour market participation, in terms of both employment and unemployment experience, is fairly important and negatively related to the probability of observing a birth. A negative sign is observed on the coefficient for the rate of unemployment in the region of residence and on that of the partner's age at marriage, which could also act as a proxy of the age of the woman at marriage. ${ }^{10} \mathrm{~A}$ strong positive effect is exhibited by the woman's number of siblings at age 14, which may be taken as a proxy for her 'taste' for children. The cohort dummies show a lower probability of childbearing for women from the birth cohorts 1960-64, 1965-69, and 1970-77 with respect to those from the oldest birth cohort (1940-44). However, because women from these cohorts are observed at relatively young ages, the statistically significant negative effects (especially for the two youngest cohorts) on childbearing may simply reflect the fact that they have decided to postpone the birth of the first child and does not imply that they will remain childless.

The job characteristics considered include weekly hours of work, the type of contract, and the occupational qualification of the woman in the job of longest duration before marriage. All these variables are found to be statistically insignificant at the conventional statistical level. This could be important as it shows that, everything else being equal, women who differ according to these job characteristics do not have a significantly different fertility behaviour, whereas these variables may have a direct association with the participation decisions after childbirth.

A formal way of testing for self-selection into motherhood when considering the labour force decisions of women after childbearing (i.e. of testing for the presence of a non-zero correlation between the unobservables affecting first birth and those influencing LFP after childbirth) is to estimate a probit model with selection, where the selection equation is represented by the decision of having a first child and the main equation is represented by a participation equation. ${ }^{11}$ In order to estimate the model and identify the LFP from the fertility equation, we include the number of siblings of the woman at age 14 in the fertility equation as a proxy for her 'taste' for children and exclude this variable from the LFP equation. ${ }^{12}$

We choose to analyse new mothers' labour market decisions by looking at participation status 1, 2, and 3 years after first birth (which correspond to 12, 24, and 36 months, respectively, in Tables 10-13). Although the choice of these three specific points in time 
may seem arbitrary, it is nevertheless representative of women's labour market behaviour during an important period of time after the birth of the first child. Indeed, as we will see (Figures 1 and 2), the predicted probabilities of participation after childbearing for each of the 36 months after the birth of the first child reveal a smooth pattern, i.e. there are no spikes at 12, 24, and 36 months, so that by showing results corresponding to these specific points in time no important aspect of the analysis is missed. ${ }^{13}$

It should also be said that the choice of a 3-year window is rather conventional in the literature as this period is long enough to describe the main features of participation following childbirth and is short enough to eliminate the influence of other events, such as a change in the marital status of an individual. ${ }^{14}$ In any case, the choice is partly dictated by the data set, as we have an indicator of the availability of childcare only for the 3 years after the birth of the first child, but after this period no information on childcare arrangements is available from the survey. ${ }^{15}$

As Table 10 shows, we do not find a significant correlation between the error terms of the participation and fertility equations at any point in time. This is so despite the fact that the effect of the number of siblings on the probability of having a birth is very significant. ${ }^{16}$ Two factors may contribute to the absence of a significant selection bias. First, there is a very high percentage of women in marital or cohabiting unions with children (more than 82 per cent ), and second it is possible that in our sample there is little individual unobserved heterogeneity left, given that we are excluding from the analysis

Table 10. Evidence on the presence of selection bias (probit with selection model)

\begin{tabular}{|c|c|c|c|c|c|c|c|c|c|}
\hline \multirow[b]{2}{*}{ Variables } & \multicolumn{3}{|c|}{12 months } & \multicolumn{3}{|c|}{24 months } & \multicolumn{3}{|c|}{36 months } \\
\hline & coef. & & st. err. & coef. & & st. err. & coef. & & st. err. \\
\hline No. of siblings & 0.365 & $* * *$ & 0.047 & 0.364 & $* * *$ & 0.047 & 0.363 & $* * *$ & 0.047 \\
\hline No. of siblings ${ }^{2}$ & -0.040 & $* * *$ & 0.007 & -0.040 & $* * *$ & 0.007 & -0.040 & $* * *$ & 0.007 \\
\hline$\rho$ & -0.162 & & 0.332 & -0.287 & & 0.323 & -0.415 & & 0.311 \\
\hline
\end{tabular}

Notes: The table shows the effect of the number of siblings living with a woman when she was aged 14 and its square value on the probability of having a first birth by 1995 , i.e. the variable that identifies the model. We indicate with $\rho$ the correlation between the error terms of the fertility and the LFP equations.

*** Significant at the 1 per cent level; ** significant at the 5 per cent level; * significant at the 10 per cent level. 
women who never worked before marriage. In order to check whether the selection we use is affecting these results, we estimate the same model on a sample of women that includes women who never worked before marriage. The results are similar to those shown in Table 10, and indicate that the correlation between the error terms of the participation and fertility equations is never statistically different from zero. ${ }^{17}$ Accordingly, in the next section we simply present the results of the estimation of a probit model without selection.

\section{Results}

In this paper, we are mainly concerned with investigating the association between job characteristics and women's labour market status in the period after childbirth. In particular, we analyse women's employment history in the period before marriage and consider how the characteristics of the job of longest duration held before marriage help to predict women's participation decisions after the birth of the first child.

For the reasons discussed in Section 4, our final model is based on a standard probit specification in which the dependent variable assumes value one if a woman is either employed or unemployed and value zero if she is out of the labour force after giving birth to her first child. Among the control variables we include the main characteristics of the job with the longest duration held by a woman before marriage, proxies for her human capital and earnings, factors related to her partner, labour demand indicators (such as the local unemployment rate), and cohort and geographic dummies. We also take into account the availability of childcare, which has been found to be an important element in explaining new mothers' labour force status.

In this final specification, we do not control explicitly for subsequent fertility, but previous analysis shows that when we include a dummy variable indicating whether the woman has a second child within 3 years since the birth of the first child ( 21 per cent of the sample) its coefficient is negative and significant at 24 and 36 months since the first birth. ${ }^{18}$ In particular, women who have a second child very soon after the first baby have about 7 percentage points lower probability of participating in the labour force than other women in our sample. However, as this variable is potentially endogenous and its exclusion from the model does not significantly alter the coefficients of interest, we decided not to include it in the final specification. ${ }^{19}$

For ease of exposition, our main results are divided into different tables. In Table 11 we present and comment on the impact of 


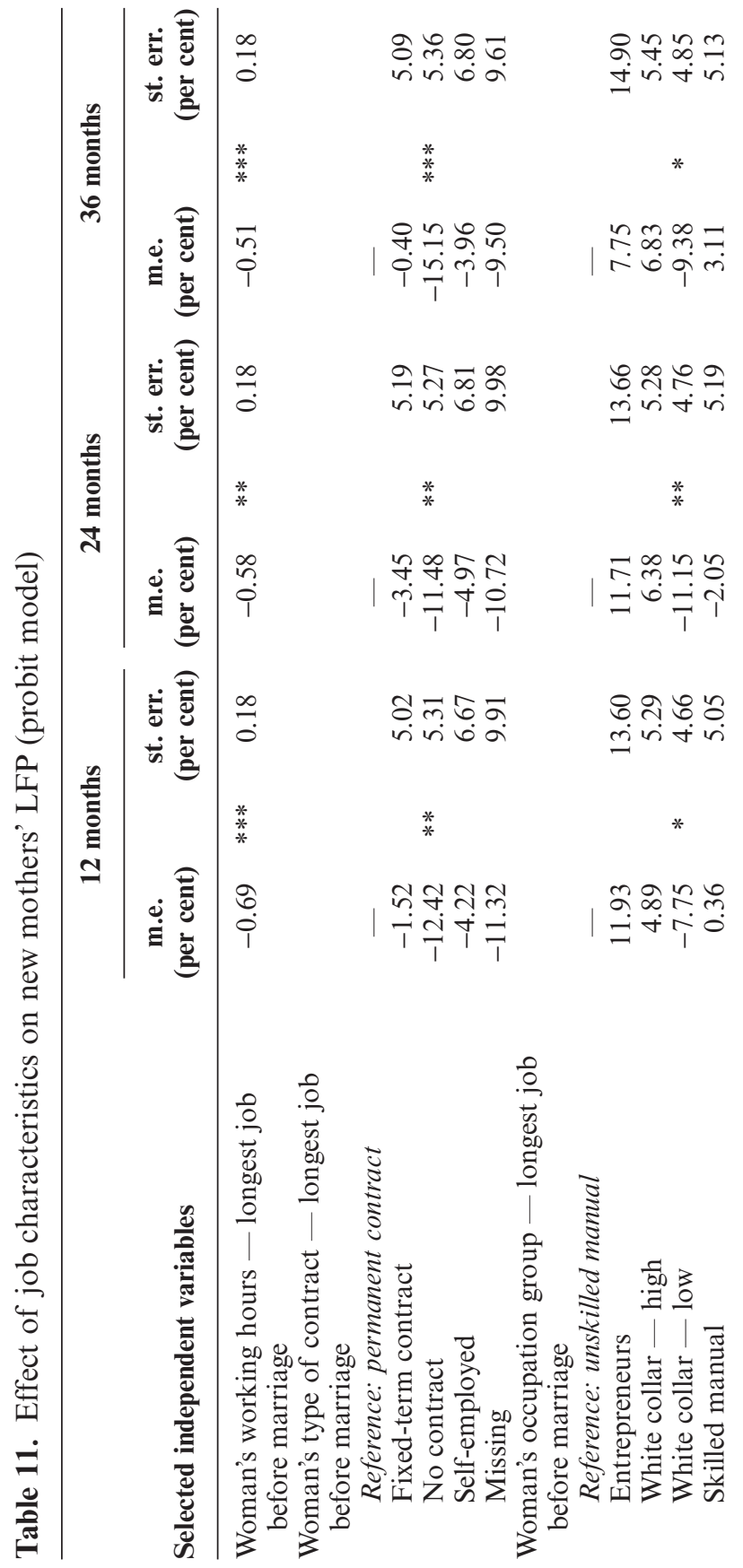




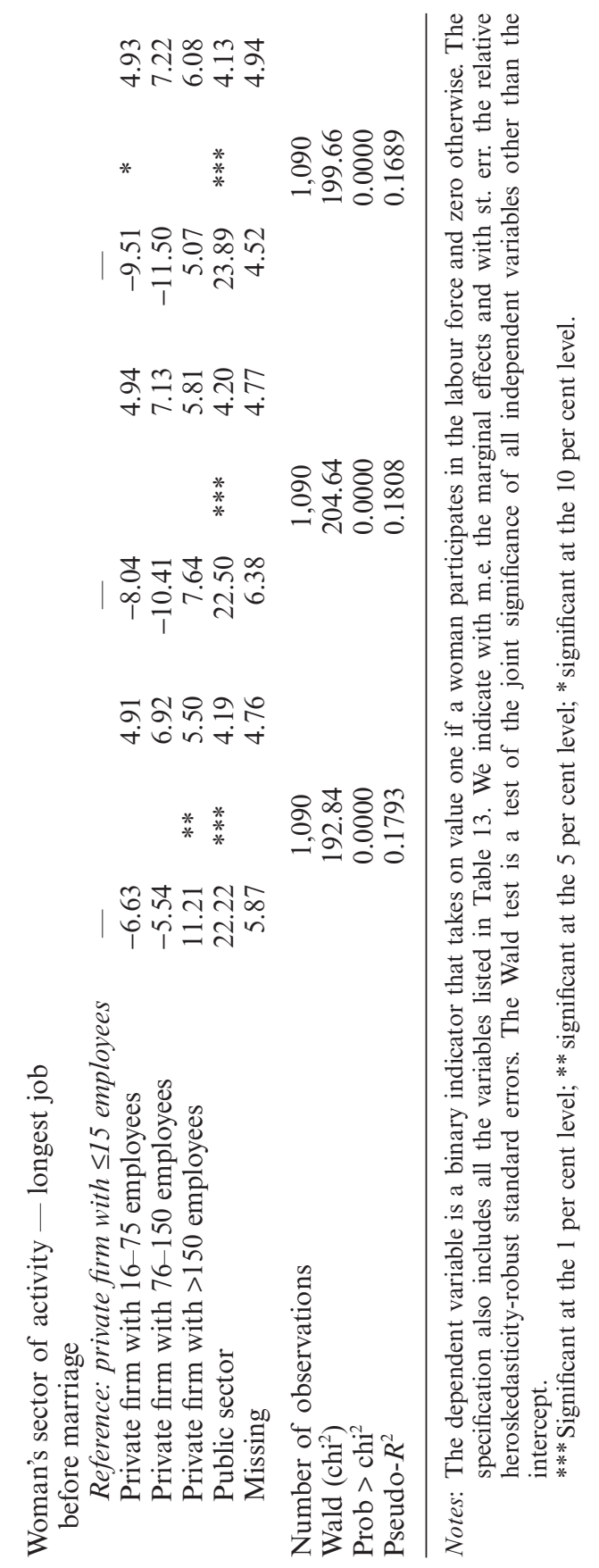

(C) CEIS, Fondazione Giacomo Brodolini and Blackwell Publishing Ltd 2005. 
Table 12. Wald tests for probit models with interaction terms

\begin{tabular}{lllll}
\hline & & \multicolumn{3}{c}{ Values ( $\boldsymbol{p}$ values) } \\
\cline { 3 - 5 } Model with interactions & Test (d.o.f.) & $\mathbf{1 2}$ months & $\mathbf{2 4}$ months & $\mathbf{3 6}$ months \\
\hline Wald tests & & & & \\
(1): public by education & $\mathrm{Chi}^{2}(3)$ & $3.45(0.33)$ & $5.02(0.17)$ & $4.36(0.22)$ \\
(2): no contract by education & $\mathrm{Chi}^{2}(3)$ & $2.76(0.43)$ & $2.69(0.44)$ & $2.59(0.46)$ \\
(3): (1) + (2) & $\mathrm{Chi}^{2}(6)$ & $6.38(0.38)$ & $7.83(0.25)$ & $6.90(0.33)$ \\
(4): public by region & $\mathrm{Chi}^{2}(2)$ & $0.48(0.76)$ & $1.64(0.44)$ & $0.75(0.69)$
\end{tabular}

Notes: Wald tests for the joint exclusion of the interaction terms. The model also includes all the covariates listed in Tables 11 and 13 .

*** Significant at the 1 per cent level; ** significant at the 5 per cent level; * significant at the 10 per cent level.

the characteristics of the job of longest duration before marriage on the probability that a woman participates in the labour market after the birth of her first child. Further checks on some of the effects of interest are presented in Table 12. Finally, Table 13 looks at the effect of other variables of interest, such as experience, childcare availability and the partner's characteristics. We comment on each table in turn below.

We see from Table 11 that some of the job characteristics are strongly related to the probability that a woman participates in the labour market after the birth of the first child. As we would expect, for instance, the number of hours worked per week is negatively associated with the probability that a new mother participates in the labour force. Because most of the women in our sample work fulltime, it is clear that any additional hour of work might make it more difficult for them to reconcile career and family responsibilities.

Among the various job characteristics considered, the type of contract is found to be one of the most important factors in predicting future participation probabilities. Women who worked without a contract (i.e. in the informal sector) in the longest job before marriage have a lower probability of working after the birth of the first child than women with a permanent contract. ${ }^{20}$ The latter appear to be between 12 and 16 percentage points more likely to be active after childbirth. This result is also represented in the top graph of Figure 1, which shows the predicted monthly probabilities of participation by type of contract for the entire 3-year window. By contrast, there is no evidence of a statistically significant penalty in the probability of participation after the birth of the 
Figure 1. Monthly predicted probabilities: type of contract and sector/size of firm
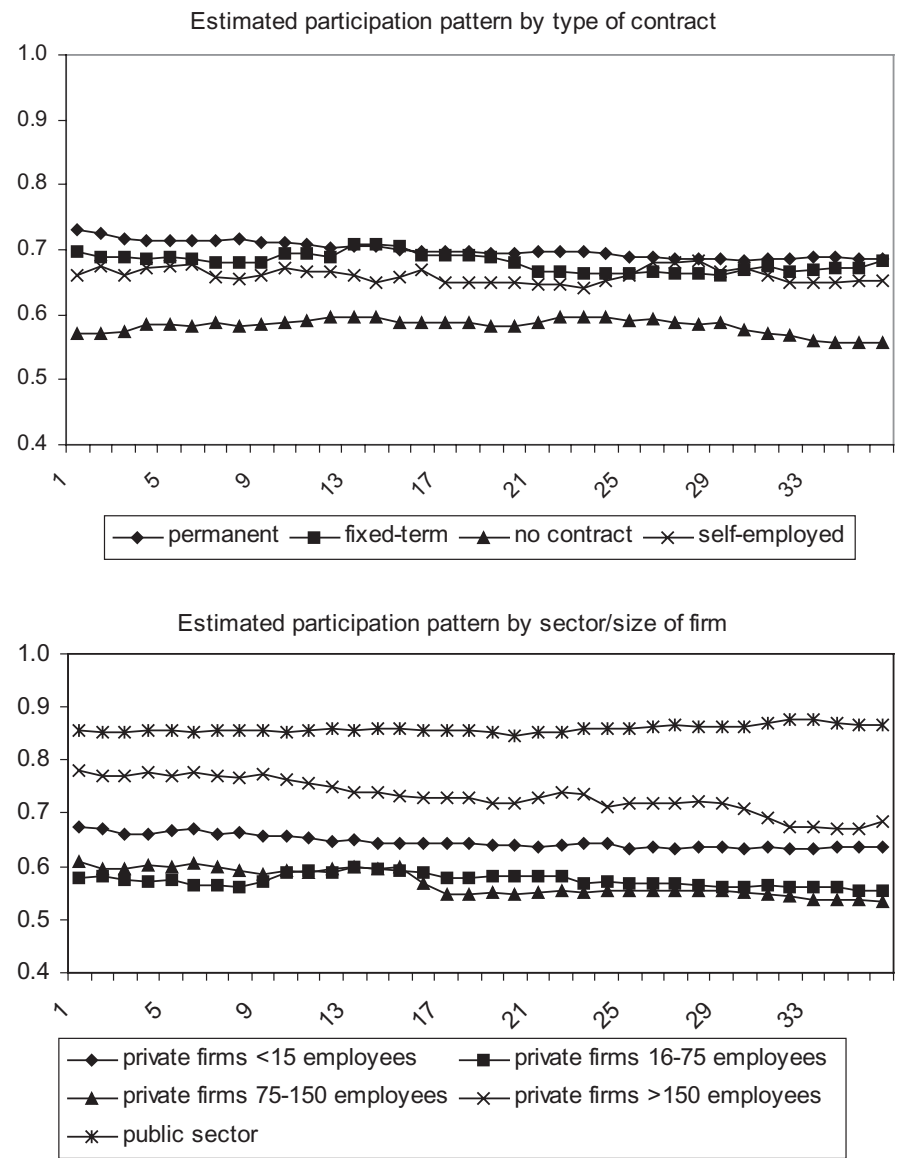

Notes: This figure shows the predicted probabilities of participating after childbirth for different values of some selected variables. Predicted probabilities are computed from monthly probit models including all the regressors in Tables 11 and 13.

first child for women who worked with a fixed-term contract or who were self-employed in their longest job before marriage with respect to women with a permanent contract.

We also tested for the statistical difference between the effect of not having a contract and that of having a fixed-term contract or being self-employed. The null hypothesis that the two coefficients 


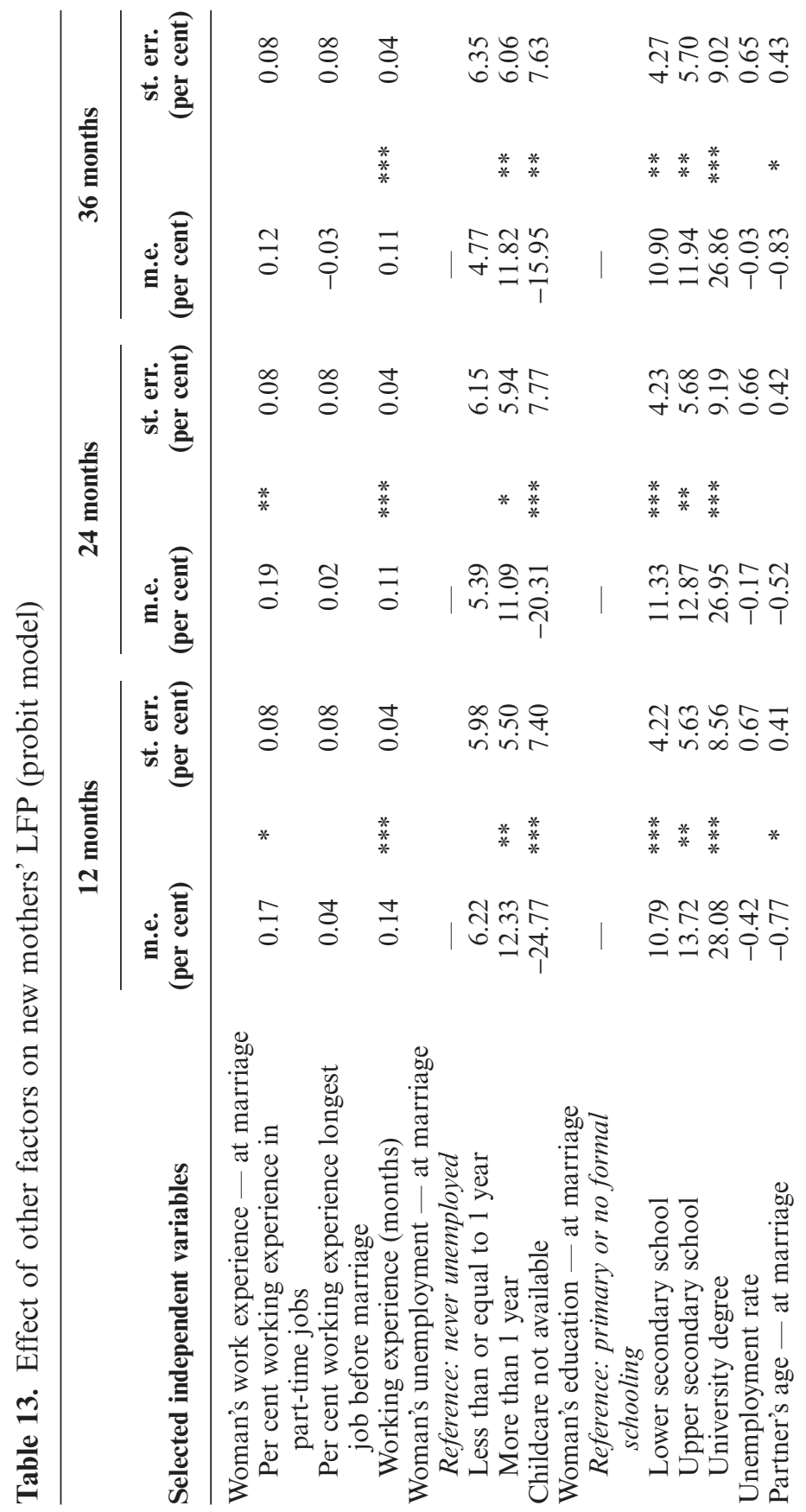




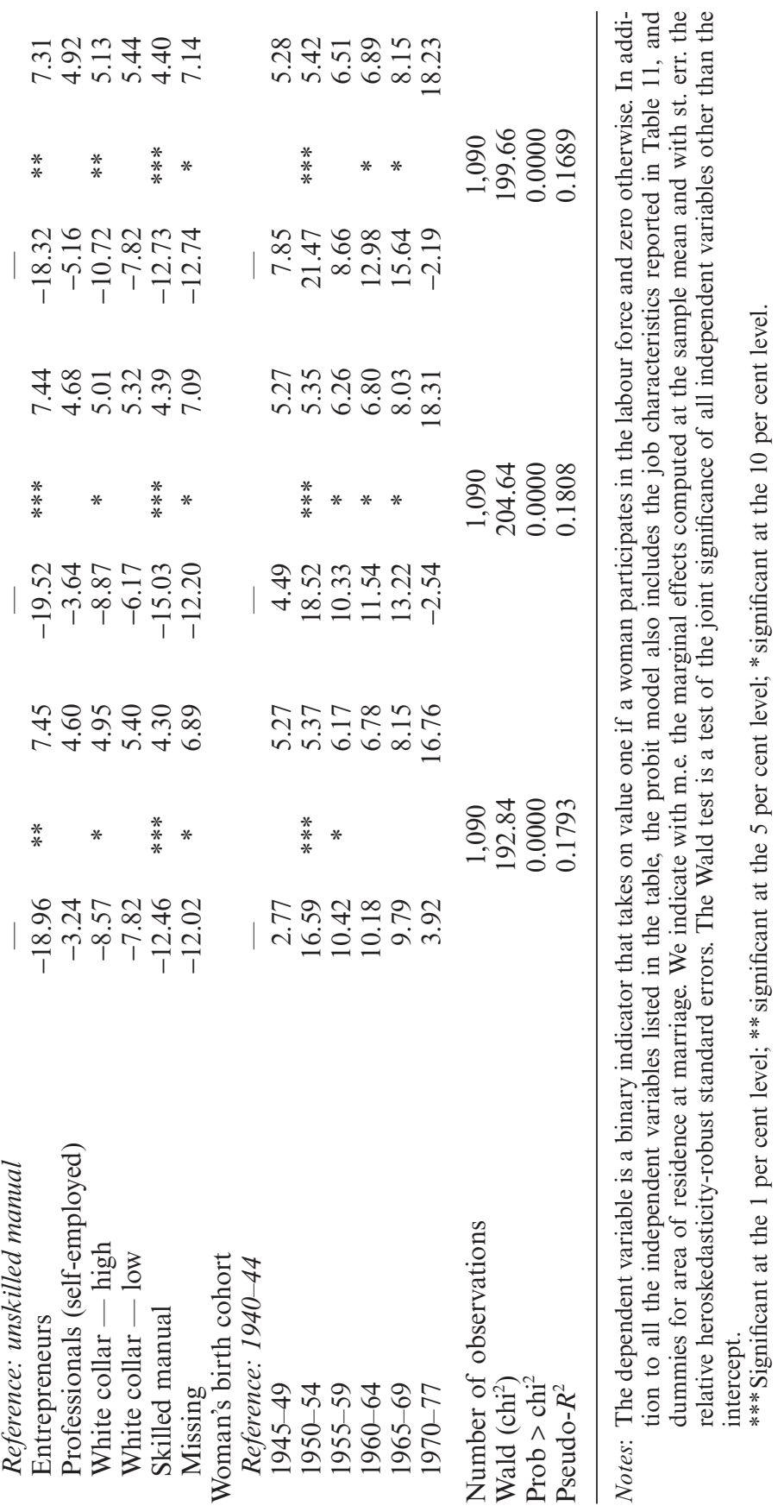

(C) CEIS, Fondazione Giacomo Brodolini and Blackwell Publishing Ltd 2005. 
are equal can be rejected in favour of the alternative hypothesis that the coefficient of the no contract category is less than that of the fixed-term contract category at 12 and 36 months (10 per cent and 5 per cent significance level, respectively), and less than that of the self-employment category at 36 months (10 per cent significance level). Therefore, there is some evidence that women without a contract are also less likely to participate after the birth of a child than women with a fixed-term contract or those who are self-employed.

When looking at occupational qualifications, we compare women in unskilled manual jobs with women in more qualified positions, who should also receive a higher wage. As we can see from Table 11 , there is no clear indication that occupational categories reflect wage differentials as the signs of the dummies are sometimes negative and sometimes positive. However, these coefficients are almost always statistically insignificant, with the exception of the dummy representing women working in low-skilled white-collar jobs who are found to have a lower probability of being in the labour force after childbirth than women working as unskilled manuals. This result may be interpreted as a higher participation of women from particularly low-income families. ${ }^{21}$

A very robust finding in our analysis is the importance of a woman's sector of activity. Table 11 shows that the public sector dummy is not only significant at the 1 per cent level, but is also one of the most important factors related to participation after childbearing in terms of the magnitude of the marginal effect. Women whose longest pre-marital job is in the public sector are between 22 and 24 percentage points more likely to be in the labour force in the first 3 years after the birth of the first child than women who work in small firms in the private sector.

If we look at the size of the firm, we see that although there is a certain non-monotonic effect on the probability of new mothers' participation, at 12 months after first birth women working in firms with more than 150 employees have a higher probability of being in the labour force after becoming mothers than employees working in small firms. This difference is also evident from the bottom graph of Figure 1, where we see clearly that women working in very large firms have a participation probability significantly higher than that of women working in small private firms especially during the first year after birth.

These differences could be attributed to the employment protection legislation, which in Italy makes a sharp distinction between small and large firms. According to Articolo 18 of the Statuto dei 
Lavoratori (Legge 300/1970), firms with more than 15 employees are required to rehire illegitimately dismissed employees and to pay them all of the wages they lost during the litigation period, whereas firms with 15 employees or less must pay just a monetary compensation to the worker if a court rules that the dismissal was illegitimate. $^{22}$

However, this still would not explain why only women working in very large firms (with more than 150 employees) show a higher LFP probability with respect to women working in firms with 15 employees or less, as the Articolo 18 also applies to firms in the size categories 16-75 and 76-150. A possible interpretation of our findings is that employees working in very large firms benefit from a much higher level of employment protection thanks to the support of the trade unions, whose presence and bargaining power is stronger than it is in relation to smaller firms. For example, the union can check the correct application of Articolo 18 by the employers and offer legal and economic support to the workers during the trial, or they can negotiate with the employer to obtain a lump-sum payment instead of going to court. If this is the case, the costs of making employees redundant would be expected to be highest for the largest firms and this could deter them from initiating a dismissal procedure and consequently grant their employees a particularly high degree of employment protection (Riley, 1997; Schivardi and Torrini, 2004). ${ }^{23}$

Although we control for several indicators of human capital in order to proxy wages, it is possible that differences in the probability of being in the labour force according to the type of contract or the sector of activity may also capture differences in wages and might not be related to differences in the degree of employment protection. Lucifora and Meurs (2004), for instance, show that the public sector pays a wage premium for low-skilled workers with respect to the private sector, whereas the opposite holds true for high-skilled workers. In order to take into account this possibility, we construct a set of interaction terms between the 'no contract' dummy and education, and another set of interactions between the 'public sector' dummy and education and include them in the probit model. ${ }^{24}$

Table 12 reports Wald tests for the joint exclusion of the interaction terms in the specifications including: (1) interactions between education and working in the public sector; (2) interactions between education and working without a contract; and (3) all the previous interactions. ${ }^{25}$ In all cases the null hypothesis cannot be rejected at conventional statistical levels. In other words, there is clearly an 
effect of working in the public sector or without a contract, which is common across workers with different levels of education, and we think that this effect could be determined by a higher degree of employment protection.

In order to further check the robustness of these results we compute interaction terms between the 'public sector' dummy and the macro-area of residence (North, Centre, South, and Islands). This is because using data from the SHIW, Alesina et al. (1999) find a wage premium for employees working in the public sector, which is higher in the South of Italy. The last row of Table 12 reports the results of the test of joint exclusion of these interaction terms, which is never rejected. Therefore, also in this case, our analysis seems to give no indication of a prevalent role of wage differences in explaining the public sector premium in the LFP probability.

Overall, we can say that the sign and significance of the variables in Table 11, which describe the characteristics of a woman's most significant pre-marital employment experience, convey the picture of a 'dual labour market'. Women with jobs providing a higher degree of employment protection find it easier to combine career and family, whereas those who occupy less regular positions and are therefore less sheltered by the legislation are more likely not to be in the labour force after first birth.

Turning now to analyse other variables, we see in Table 13 that past labour market experience - here captured by variables such as the cumulative experience of employment or unemployment at marriage, the percentage of the period spent in the job with the longest duration, and the percentage of the period spent in part-time jobs over total labour market experience at marriage - is very important in predicting participation choices after childbearing. In particular, an increase of one percentage point in the fraction of pre-marital working experience spent in part-time employment is significantly associated with a premium in the probability of working at 12 and 24 months after childbirth of, respectively, 0.17 and 0.19 percentage points. Similarly, we see that an increase in overall working experience is significantly and positively related to the probability of being in the labour force after the birth of the first child.

We also find that women who have experienced long periods of unemployment before marriage are generally more likely to participate after becoming mothers than women who have never been unemployed. This effect could indicate a strong propensity to participate for this group of subjects. However, further analysis of this result shows that women with longer pre-marital unemployment 
experience are more likely to be unemployed after the birth of the first child. Thus, it is possible that this effect simply results from the fact that a few individuals in our sample register very long unemployment spells that are not interrupted even after the birth of the first child.

As shown in several studies (Del Boca, 2002; Del Boca et al., 2005; Duncan and Giles, 1996; Marenzi and Pagani, 2005), childcare availability is a very important factor for the reconciliation of career and family responsibilities. Therefore, in all our specifications we include a dummy for the absence of institutional and informal childcare as an explanatory variable. The results show that the lack of childcare opportunities is negatively and highly significantly correlated with the probability of being active following childbirth. The estimated marginal effect on the probability of participation is of $-25,-20$, and -16 percentage points, respectively, at 12,24 , and 36 months after childbirth.

This result is also graphically represented in the top graph in Figure 2, which shows the predicted monthly probabilities of participation by availability of childcare for the whole 3-year window. The figure reveals that women who do not have access to childcare experience a decrease in the probability of being in the labour force after childbirth especially shortly after the end of the compulsory leave period and after 12 months since the birth of the child, i.e. after the optional leave period. Since these cut-off points determine the end of the compulsory and the optional maternity leave, respectively, this variable captures an important effect of the maternity leave legislation, which in Italy represents the main form of institutional assistance provided to mothers as childcare facilities are extremely scarce for children below 3 years of age.

Consistently with what has been found in many other studies (see among the others Bratti, 2003; Dex et al., 1998; Klerman and Leibowitz, 1994), we find that the highly educated women have a higher LFP. In particular, women with a university degree are 28 percentage points more likely to participate at 12 months after birth than those with only primary or no educational qualifications. ${ }^{26}$ The effect is very similar also at 24 and 36 months, resulting in a constantly higher predicted probability of being active after childbearing over the entire 3-year period as shown in the bottom graph of Figure 2. The premium in the probability of participating for women with upper or lower secondary schooling is somewhat smaller, but always very significant with respect to women with low levels of education. 
Figure 2. Monthly predicted probabilities: childcare and education
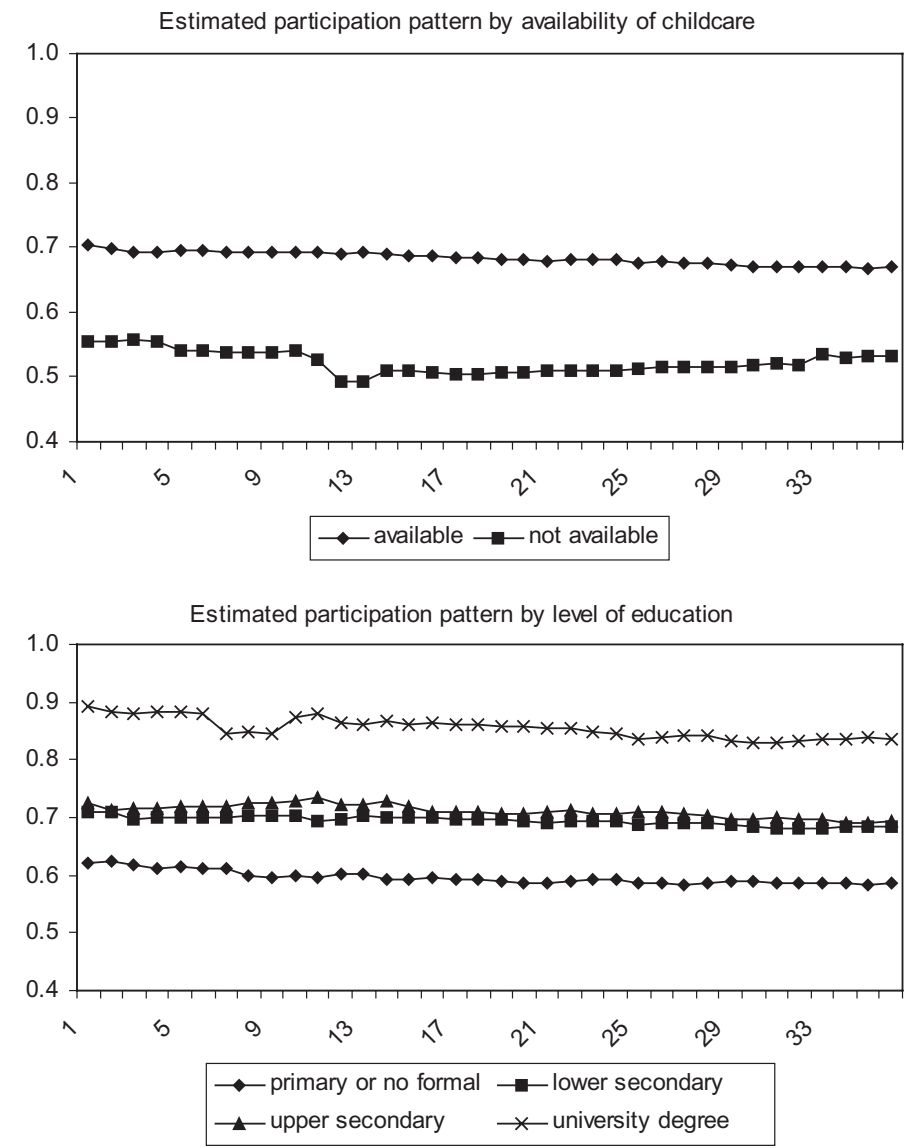

Notes: This figure shows the predicted probabilities of participating after childbirth for different values of some selected variables. Predicted probabilities are computed from monthly probit models including all the regressors in Tables 11 and 13.

From Table 13, we also see that the husband's characteristics are quite important in order to capture income effects. A woman whose partner is an entrepreneur, a high white collar, or a skilled manual worker has a significantly lower probability of being in the labour force after childbirth than a woman whose partner is an unskilled manual worker. ${ }^{27}$ 
The coefficients on the cohort dummies show that younger cohorts generally have a higher probability of LFP after first childbirth, although the effect is not monotonically increasing over time and is not statistically significant for some cohorts. This suggests the existence of a trend towards an increasing LFP over time. As we already discussed, the coefficients on the youngest cohorts (which are observed in our sample for a shorter time span and only at young ages) are hardly interpretable as cohort effects because they mix cohort and age effects. Nonetheless, the estimates show that, after accounting for observable characteristics, the youngest cohort (1970-77) does not have a significantly lower LFP probability than the 1940-44 cohort contrary to the raw data in Table 2 seemed to suggest.

Overall, our main results show that the factors associated with women's probability of participating after childbirth do not change dramatically across the 3 -year window considered. This implies that there are long-term effects of various characteristics of the woman's longest job before marriage, like the type of contract and the sector of activity on the probability of being in the labour force after childbearing. Indeed, as the factors explaining LFP after childbearing are similar throughout this period, our analysis implicitly confirms that, unlike the UK where the typical choice is one of interrupted employment (Joshi et al., 1996), in Italy women who exit the labour market do not immediately re-enter it.

To conclude, we compare the results above with those obtained using the characteristics of the last job at marriage and those of the last job before childbearing, reported, respectively, in Tables A1 and A2 in the Appendix. As we can see, the signs and the magnitudes of the coefficients associated with the variables of interest do not change very much across specifications, suggesting that the substantial lack of mobility in the Italian labour market makes it equivalent in terms of our analysis which job episode preceding the birth of the child one chooses. The main difference is found when looking at the firm size. Here the difference between small and large firms is even more important than what we saw in Table 11. In this case, employees working in large firms have a significantly higher probability of participating after childbearing that lasts for the entire 3-year window considered. This could be explained by the fact that the last jobs at marriage or at childbearing are probably better proxies of women's working conditions at the time of childbearing and are therefore better suited to reflect the impact of the employment protection legislation. 


\section{Conclusions}

In this paper we use individual-level data from the LSIH to investigate the factors associated with female LFP after the birth of the first child. Because the LSIH gathers retrospective data on the entire working history of the women in the survey, we use this information to assess the importance of pre-marital job characteristics in explaining new mothers' labour market participation decisions in the period immediately following childbirth.

We find that several job-related factors have an important explanatory power with respect to new mothers' participation decisions. In particular, working in the public sector or in large firms is positively correlated with women's participation after childbearing, whereas working without a contract is negatively associated with it. We try to determine whether these results are simply due to earnings differences across women, which cannot be captured by other control variables, by including interaction terms between education and the most important job attributes. Assuming that these interaction terms are a good proxy of wage differences among jobs with the same characteristics, we find that wage effects are not what drives our results. We therefore suggest that the role of these job characteristics may reflect different levels of employment protection enjoyed by workers.

These findings convey the picture of a 'dual labour market' whereby women who enjoy a substantial amount of employment protection have a higher incentive to participate in the labour force in the period immediately following childbirth, whereas women who find themselves in less protected and secure jobs are more likely to be inactive. This would imply that recent reforms of the Italian labour market, such as the 'Pacchetto Treu' (Legge 196/1997) or the 'Riforma Biagi' (Legge 30/2003), which aim at increasing labour market flexibility and the employability of young and female workers, might reduce the expected benefits from employment for new mothers and have unintended negative consequences on their LFP unless they are accompanied by measures that provide a sufficient degree of employment protection. 


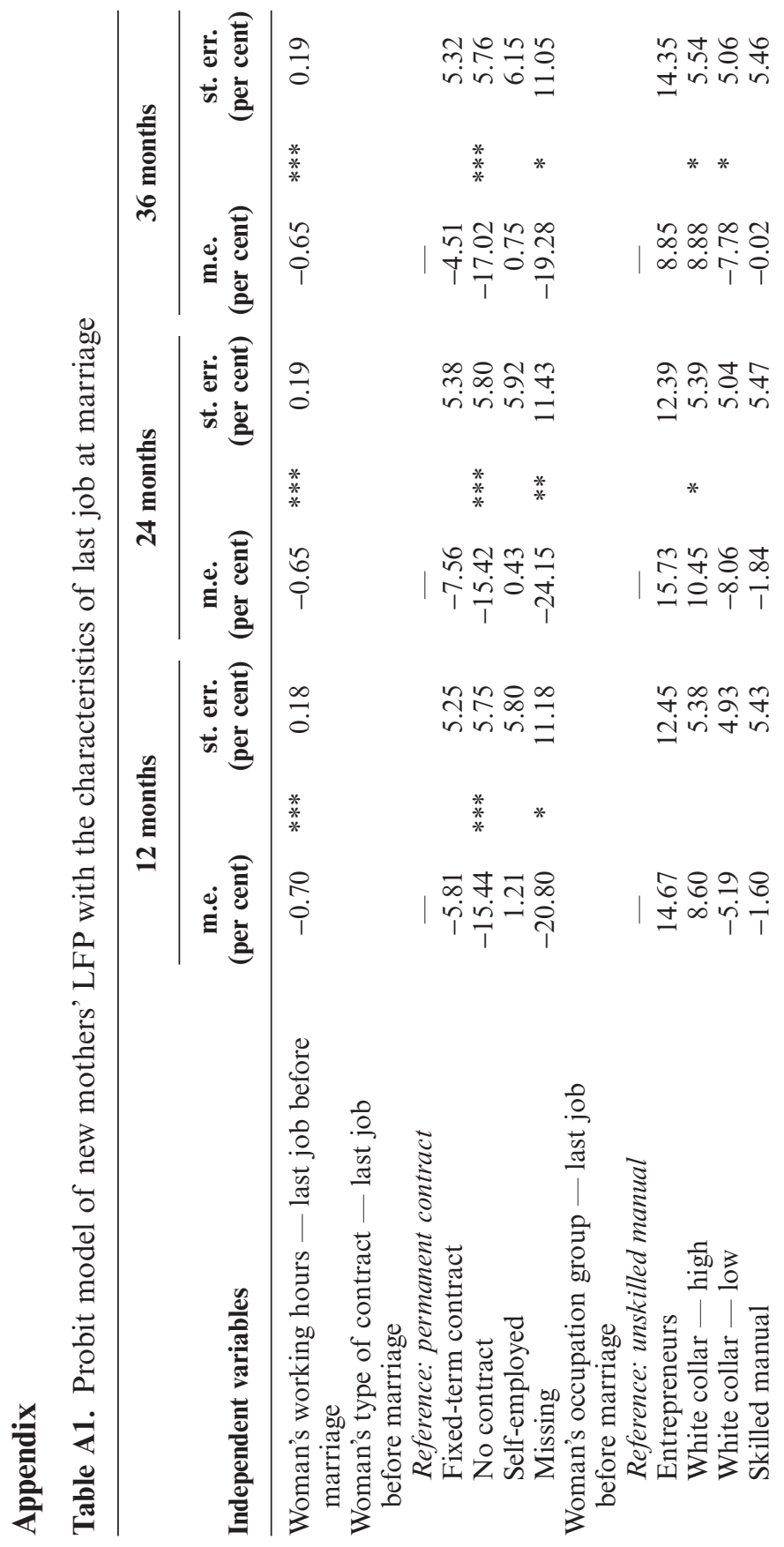

(C) CEIS, Fondazione Giacomo Brodolini and Blackwell Publishing Ltd 2005. 


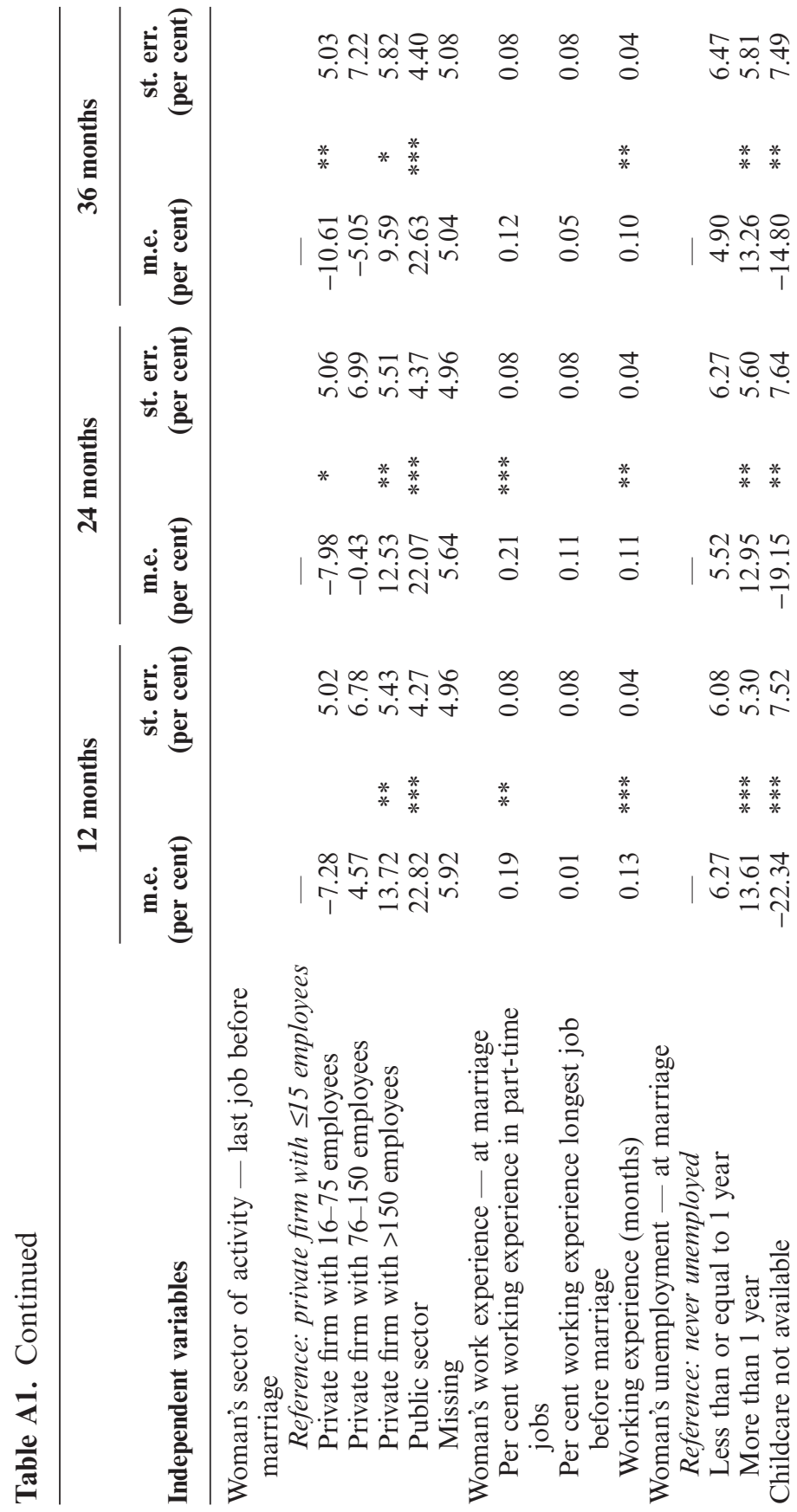




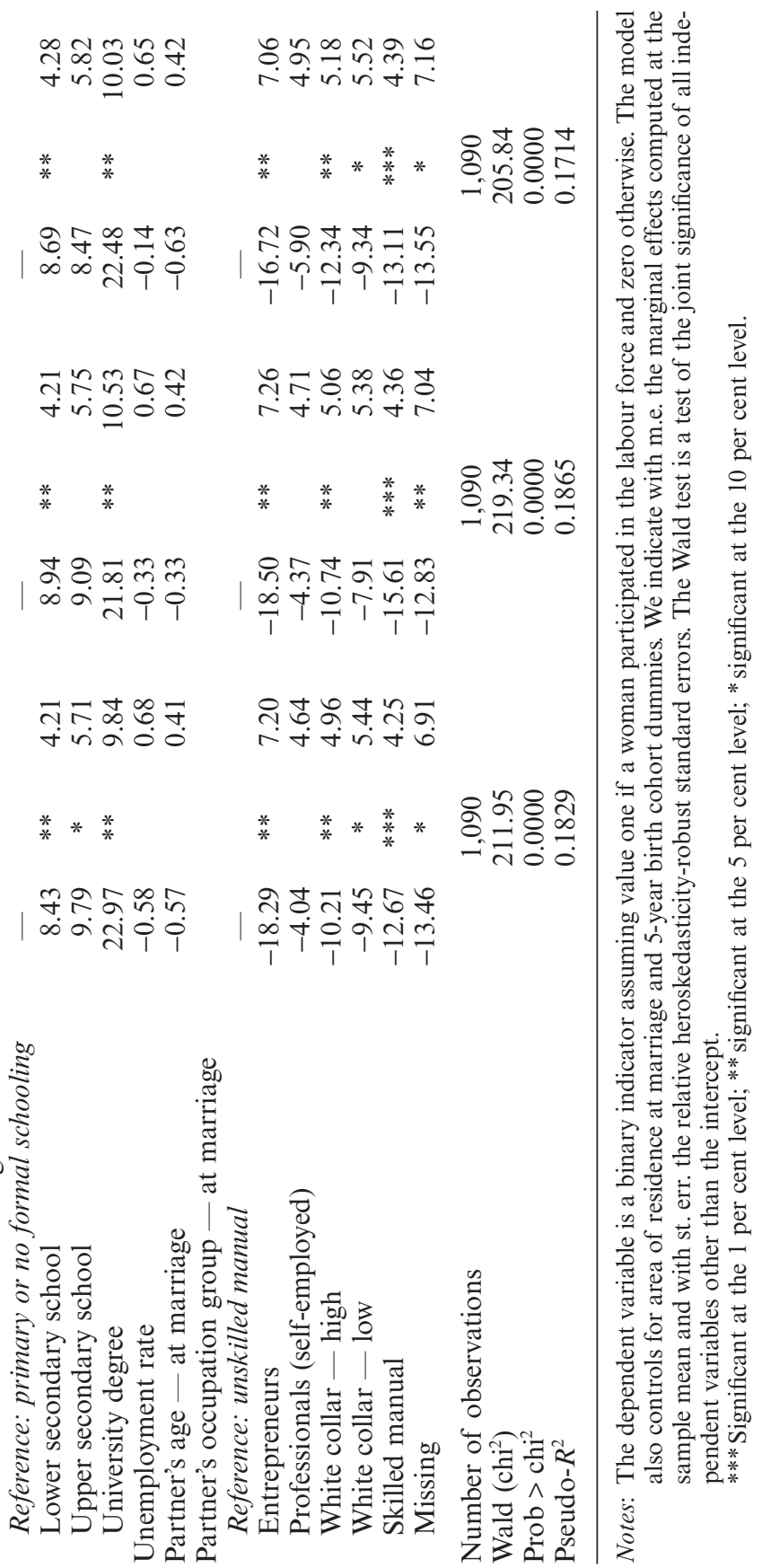

(C) CEIS, Fondazione Giacomo Brodolini and Blackwell Publishing Ltd 2005. 


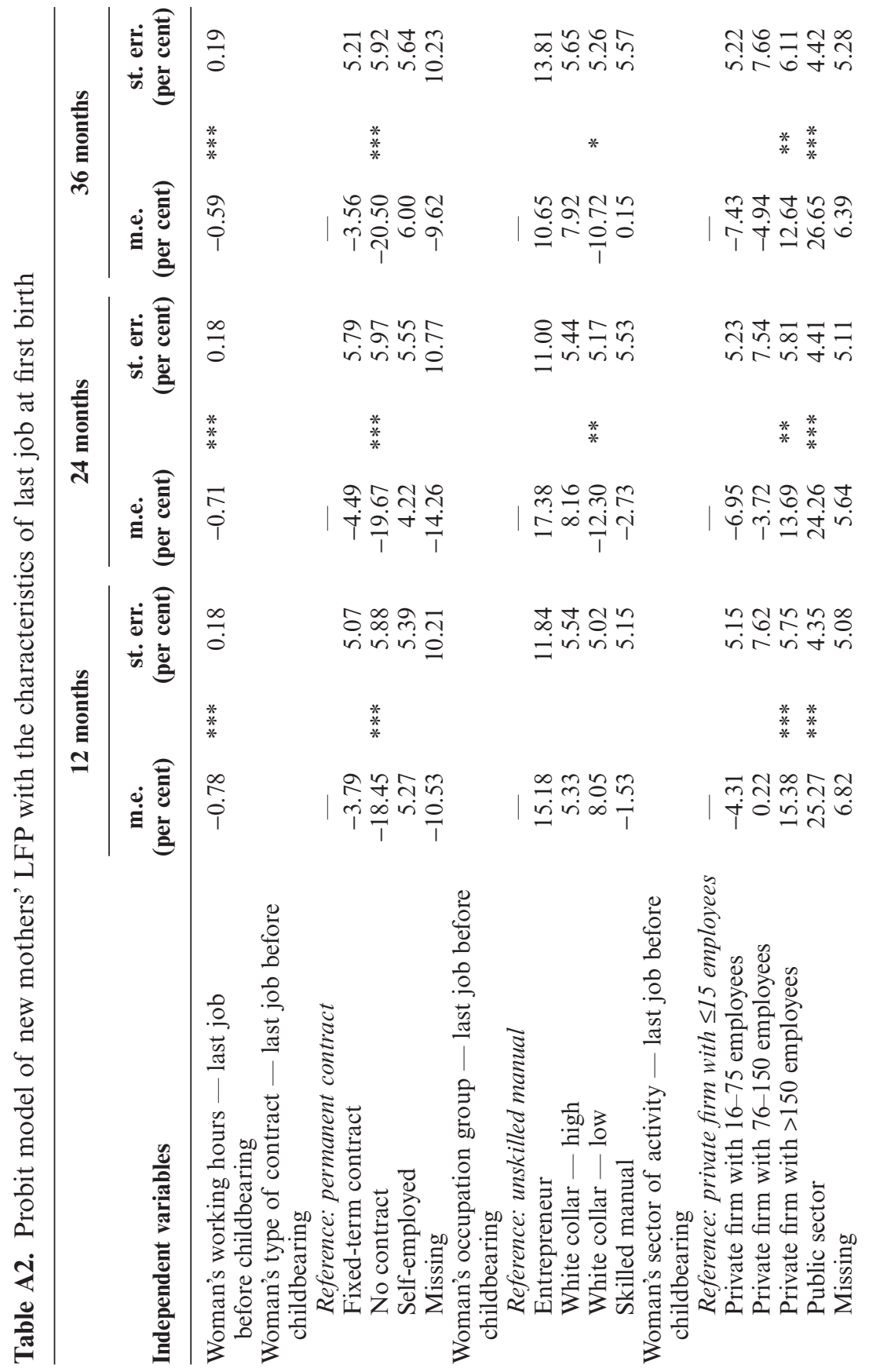

(C) CEIS, Fondazione Giacomo Brodolini and Blackwell Publishing Ltd 2005. 


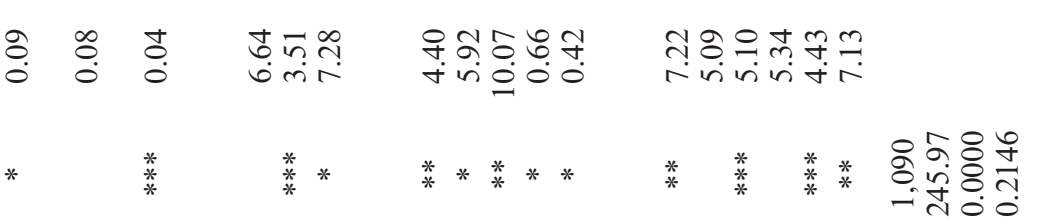

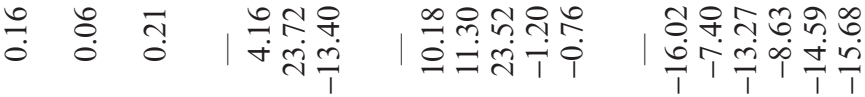

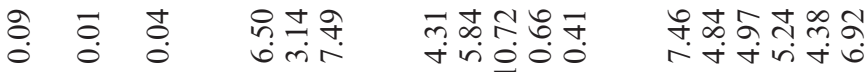

$$
\begin{aligned}
& \text { * * * * * * *** * * * * * * * }
\end{aligned}
$$

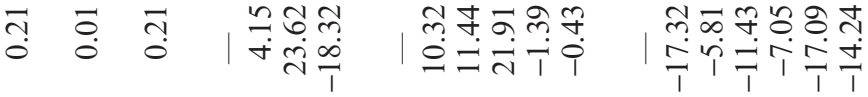

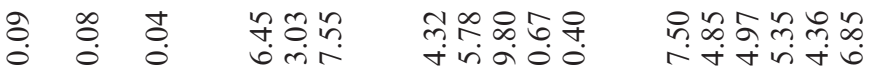

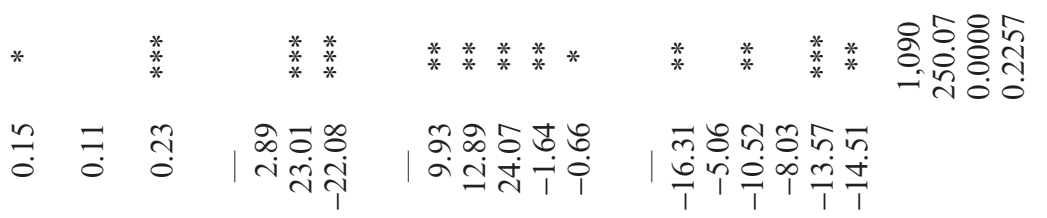

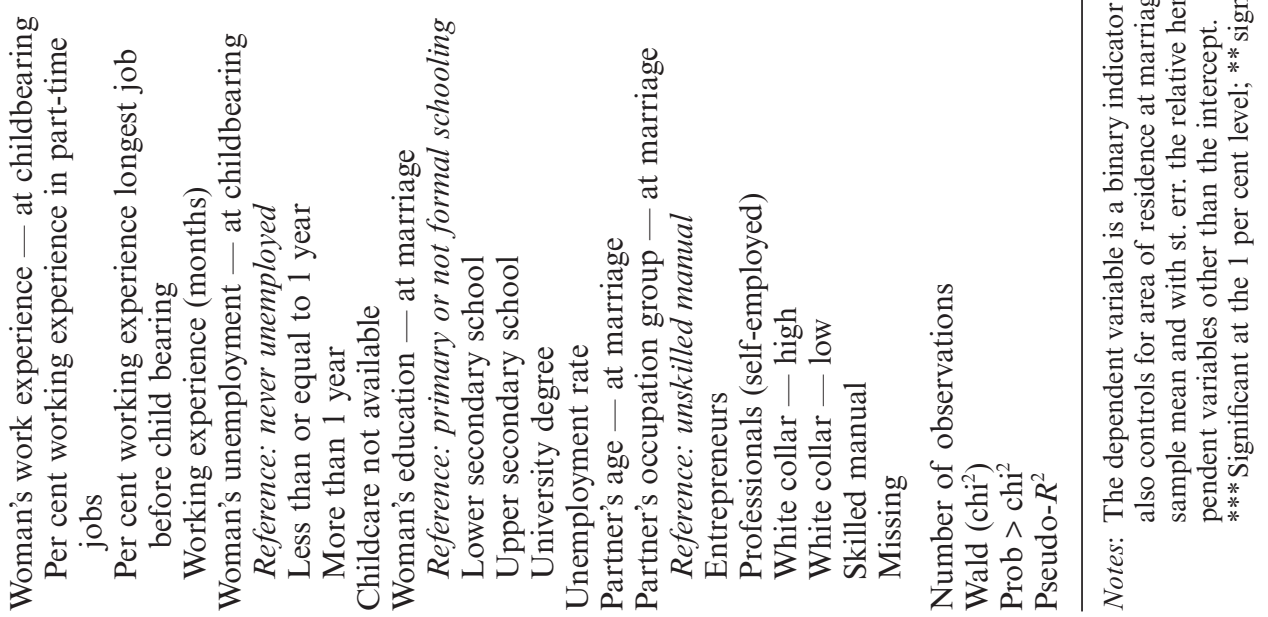




\section{Notes}

${ }^{1}$ Indagine Longitudinale sulle Famiglie Italiane.
${ }^{2}$ Such as Del Boca (2002), Del Boca et al. (2005), Marenzi and Pagani
(2005).
${ }^{3}$ For a more detailed description of the data and the structure of the survey, see
Schizzerotto (2002).
${ }^{4}$ Out-of-wedlock births, which include births in co-habiting unions, were about 9 per cent of total live births in 1997 (see ISTAT, 2002), but this percentage was much lower in previous decades (for instance, only slightly above 4 per cent in 1980).

${ }^{5}$ We decide not to draw a distinction between co-habiting and married couples as co-habitation is a very recent phenomenon in Italy, and we will simply refer to marriage to address both types of unions.

${ }^{6}$ This provides for a period of compulsory leave that lasts 5 months $(2$ months before and 3 months after the birth) and during which the woman is entitled to 80 per cent of her salary, and an additional period of optional leave that can last up to 6 months (until the child's first birthday) and during which the remuneration falls to 30 per cent of the usual take-home pay (Legge 1204/1971). Because the average year of birth of the child in our sample is 1980, and more than threequarters of births occur after 1971, this law applied to the vast majority of mothers in our sample. The legislation on parental leave in Italy has been recently modified (Legge 53/2000), but the new law came into effect after the end of our observation period and therefore it did not affect the behaviour of the individuals included in our analysis.

${ }^{7}$ In an earlier version of this paper we included in our sample women who had never worked before marriage and used a dummy variable in order to identify this group. The dummy had a negative and significant effect on the probability of being in the labour force after childbirth, but all other results were not qualitatively different from those reported in the present analysis.

${ }^{8}$ The table also shows relatively low rates of female participation for the two youngest cohorts. This likely results from the fact that women from these cohorts might be a selected sample of the population of reference. This is because when we consider the birth cohorts 1965-69 and 1970-77, only women who gave birth relatively early in their life enter the sample. Indeed, Table 1 shows that women from these birth cohorts account only for about 8 per cent of our sample.

${ }^{9}$ Both the number of siblings and its square are included in the probit model. Both coefficients turn out to be statistically significant. We report the marginal effect of the number of siblings computed as follows. If we indicate with $\operatorname{Pr}(Y=1)$ the probability of the outcome of interest, where $Y$ is the binary dependent variable under study, with $X$ the vector of regressors, and with sib the number of siblings, we can compute the marginal effect of sib as

$$
\frac{\partial \operatorname{Pr}(Y=1)}{\partial s i b}=\phi\left(\gamma X+\beta_{1} s i b+\beta_{2} s i b^{2}\right)\left(\beta_{1}+2 \beta_{2} s i b\right)
$$

which is then evaluated at the sample mean of all covariates. As we estimate a probit model, $\phi(\cdot)$ is the standard normal density function, and $\beta_{1}$ and $\beta_{2}$ are simply the coefficients of $s i b$ and $s i b^{2}$, respectively. Standard errors are computed using the delta method. 
${ }^{10} \mathrm{We}$ do not include woman's age at marriage because it turns out to be highly collinear both with her partner's age at marriage and with her labour market experience.

${ }^{11}$ See van de Ven and van Praag (1981).

${ }^{12}$ Exclusion restrictions are not necessary when the model is estimated by parametric methods, but they are generally thought to be important in order not to rely only on functional form assumptions.

${ }^{13}$ It is possible that, by estimating the probability of participation at a particular point in time during a 3-year window instead of the probability of a transition between activity and inactivity over this period, we are discarding potentially important information. For example, we could have chosen to estimate a duration model where the dependent variable is given by the length of time in the labour force after the birth of the child. However, we think that such a model would not offer significant advantages in our case, because the window of 3 years is a relatively short period and Italian women experience relatively few transitions in and out of the labour force with respect to women in other countries, such as the UK (Solera, 2003).

${ }^{14}$ During the period under study a divorce decree would usually take $3-5$ years to become absolute.

${ }^{15}$ We carried out an additional analysis on a 5-year window (excluding our indicator for childcare availability) and did not find major qualitative differences with respect to the results reported here.

${ }^{16}$ As a further check of the validity of our exclusion restriction, we looked at the effect of the number of siblings in a simple participation equation and found that this variable is not statistically significant in that context.

${ }^{17}$ These results are available upon request from the authors.

${ }^{18} \mathrm{~A}$ different approach is followed by Dex et al. (1998), Gutiérrez-Domènech (2002), and Shapiro and Mott (1994) among others.

${ }^{19}$ These results are available upon request from the authors.

${ }^{20}$ We should not think of the informal sector as a way in which women can negotiate more flexible hours or working conditions that are more compatible with child-rearing activities. In our sample, women working without a regular contract are mainly employed in a full-time job ( 85 per cent), and work over the entire year (92 per cent), whereas only a handful of them work from home (4 per cent). Some of these women are in very unskilled jobs, such as domestic or office cleaners (12.98 per cent), or work as agriculture ( 8.16 per cent) or manufacturing ( 2.72 per cent) labourers. A sizeable proportion of them performs semi-skilled jobs, such as tailoring (9.56 per cent), or is employed in the textile industry as machine operators (12.24 per cent), but there is also a more skilled group that consists of secretaries ( 6 per cent), childcare workers ( 3.4 per cent), hairdressers/beauticians (4 per cent), and shop salespersons (11.56 per cent).

${ }^{21}$ Because the general lack of significance of these variables may be driven by the correlation between the partners' occupational qualification variables (under the hypothesis of positive assortative mating), we also estimate our model excluding the husband's occupational qualification variables and calculate the corresponding marginal effects. As in Table 11, also in this case only the dummy for women working in low-skilled white-collar jobs turns out to be statistically significant with a marginal effect of the same magnitude as in the previous specification: -0.082 ( $p$ value: 0.075$)$ at 12 months, -0.112 ( $p$ value: 0.017 ) at 24 months, and -0.100 ( $p$ value: 0.035 ) at 36 months. 
${ }^{22}$ More than 80 per cent of children in our sample were born after 1970, so that their mothers would have been covered by the rules of the Statuto dei Lavoratori.

${ }^{23} \mathrm{We}$ are grateful to an anonymous referee for suggesting this possible interpretation.

${ }^{24} \mathrm{We}$ also tried to construct interactions between the 'no contract' dummy and the occupational qualifications and between the public sector dummy and the occupational qualifications, but because of small cell size and multicollinearity problems (i.e. almost all employees in the public sector are white-collar workers), these results were not very robust.

${ }^{25}$ Full regression results are available upon request from the authors.

${ }^{26}$ Using data from the SHIW and focusing on women aged 21-39 only but considering also women who never participated in the labour force, Bratti (2003) estimates a similar strong effect of women's education on LFP.

${ }^{27}$ Other studies finding a negative husbands' income effect for Italy are, for instance, Colombino and Di Tommaso (1996) and Di Tommaso (1999).

\section{References}

Alesina A., Danninger S. and Rostagno M. V. (1999) 'Redistribution through Public Employment: The Case of Italy', NBER Working Paper 7387, National Bureau of Economic Research, Cambridge, MA.

Becker G. S. (1981) A Treatise on the Family, Cambridge, MA: Harvard University Press.

Berg P., Kalleberg A. L. and Appelbaum E. (2003) 'Balancing Work and Family: The Role of High-commitment Environments', Industrial Relations 42: $168-188$.

Bratti M. (2003) 'Labour Force Participation and Marital Fertility of Italian Women: The Role of Education', Journal of Population Economics 16: $525-554$.

Cigno A. (1991) Economics of the Family, Oxford: Clarendon Press.

Colombino U. and Di Tommaso M. L. (1996) 'Is the Preference for Children So Low or Is the Price of Time So High? A Simultaneous Model of Fertility and Participation in Italy with Cohort Effects', Labour 10: 475-493.

Del Boca D. (2002) 'The Effect of Child Care and Part Time Opportunities on Participation and Fertility Decisions in Italy', Journal of Population Economics 15: 549-573.

Del Boca D. and Vuri D. (2005) 'Labor Supply and Child Care Costs: The Effect of Rationing', IZA Discussion Paper 1779.

Del Boca D., Locatelli M. and Pasqua S. (2000) 'Employment Decisions of Married Women: Evidence and Explanations', Labour 14: 35-52.

Del Boca D., Locatelli M. and Vuri D. (2005) 'Child Care Choices by Working Mothers: The Case of Italy', The Review of Economics of the Household Institute for the Study of Labor, Bonn 3: 453-477.

Desai S. and Waite L. J. (1991) 'Women's Employment during Pregnancy and after the First Birth: Occupational Characteristics and Work Commitment', American Sociological Review 56: 551-556. 
Dex S., Joshi H., Macran S. and McCulloch A. (1998) 'Women's Employment Transitions around Childbearing', Oxford Bulletin of Economics and Statistics 60: 79-98.

Di Tommaso M. L. (1999) 'A Trivariate Model of Participation, Fertility and Wages: The Italian Case', Cambridge Journal of Economics 23: 623-640.

Duncan A. and Giles C. (1996) 'Should We Subsidise Pre-school Childcare, and if So, How?', Fiscal Studies 17: 39-61.

Gutiérrez-Domènech M. (2002) 'Employment Penalty after Motherhood in Spain', CEP Discussion Paper 1177, Centre for Economic Performance, London.

ISTAT (2002) Annuario Statistico Italiano 2002, Rome: ISTAT.

Joshi H., McRae S. and Dex S. (1996) 'Employment after Childbearing and Women's Subsequent Labour Force Participation: Evidence from the 1958 British Cohort', Journal of Population Economics 9: 325-348.

Klerman J. A. and Leibowitz A. (1994) 'The Work-employment Distinction among New Mothers', Journal of Human Resources 24: 277-303.

Lucifora C. and Meurs D. (2004) 'The Public Sector Pay Gap in France, Great Britain and Italy', IZA Discussion Paper 1041, Institute for the Study of Labor, Bonn.

Marenzi A. and Pagani L. (2005) 'The Impact of Elderly Parents on Labour Market Participation of Italian Women', Rivista di Politica Economica 3/4.

Nakamura A. and Nakamura N. (1992) 'The Econometrics of Female Labour Supply and Children', Econometric Reviews 11: 1-71.

Nakamura J. and Ueda A. (1999) 'On the Determinants of Career Interruption by Childbirth among Married Women in Japan', Journal of the Japanese and International Economies 13: 73-89.

Riley, N.-M. (1997) 'Determinants of Union Membership: A Review', Labour 11: 265-301.

Schivardi F. and Torrini R. (2004) 'Firm Size Distribution and Employment Protection Legislation in Italy', Temi di Discussione del Servizio Studi n. 504, Bank of Italy.

Schizzerotto A. (2002) Vite ineguali. Disuguaglianze e corsi di vita nell'Italia contemporanea, Bologna: Il Mulino.

Shapiro D. and Mott F. (1994) 'Long-term Employment and Earnings of Women in Relation to Employment Behavior Surrounding the First Birth', Journal of Human Resources 29: 248-275.

Solera C. (2003) 'Changes in Women's Work Histories across Cohorts: To What Extent Are They Due to a Compositional Effect? A Comparison of Italy and Great Britain', EUI Working Paper SPS, 04/09.

van de Ven W. P. and van Praag B. M. (1981) 'The Demand for Deductibles in Private Health Insurance: A Probit Model with Sample Selection', Journal of Econometrics 17: 229-252. 